\title{
OROGÊNESES PRECEDENDO E TAFROGÊNESES SUCEDENDO RODINIA NA AMÉRICA DO SUL
}

\author{
B.B.Brito Neves ${ }^{1}$; M.Winge ${ }^{2}$; M.A.Carneiro ${ }^{3}$
}

PALAVRAS-CHAVE: Uruaçuano, Espinhaço, Rodinia, orogenias, cráton.

BRITO NEVES, B.B. et al. (1996) Orogêneses precedendo e tafrogêneses sucedendo Rodinia na América do Sul. Bol.IG-USP, Sér.Cient., 27:1-40.

\section{RESUMO}

Evidências de uma colagem orogênica de amplitude mundial, como a de Grenville, têm sido apontadas na América do Sul, ao longo do embasamento andino, da Colômbia ao noroeste argentino, e ainda na fronteira Brasil-Bolívia (sudoeste do Cráton Amazônico).

Alguns novos dados geológicos e geocronológicos, inclusive de teses ainda inéditas, e a revisăo do acervo de dados preexistentes sugerem para o interior de nosso continente a ocorrência de um processo colisional importante, e de outros eventos subordinados (no Maciço Central Goiás-Tocantins, na parte central do Cráton do São Francisco) no mesmo intervalo de tempo - periodo Ectasiano (em torno de $1300 \mathrm{Ma}$ ). Os sítios preferenciais (mas não exclusivos) para estes processos de convergência, colisāo e transpressão foram aqueles dos riftes e bacias gerados na tafrogênese do Estateriano (1800$1600 \mathrm{Ma}$ ), no final do Paleoproterozóico.

Tais processos de orogênese, que haviam sido preliminarmente designados de "Uruaçuano" (Brasil Central) e "Espinhaço" (Bahia e Minas Gerais), sob muitas imprecisōes da época, estăo agora sendo ratificados e reconhecidos como parte de um amplo contexto de interação convergente de placas e subplacas litosféricas, responsável por importante retrabalhamento de rochas do embasamento (rochas do Paleoproterozóico sobretudo) e a edificação de orógenos, com uma fase significativa pósdeformacional de erosão no Mesoproterozóico (com extensão no tempo ao Neoproterozóico), a qual precede francamente o ciclo orogênico subseqüente (Brasiliano).

Neste trabalho estes processos orogenéticos da segunda metade do mesoproterozóico estăo sendo reconhecidos como equivalentes àqueles do Ciclo Grenville, guardando certo paralelismo com este no interior do nosso continente. Eventos concomitantes e subordinados de ativação dos blocos cratônicos adjacentes a estas orogenias, tais como cisalhamento, basculamentos, rejuvenescimento termal e isotópico, etc., já haviam também sido identificadas de há muito, neste intervalo do tempo, como reflexos naturais dos gradientes tectônicos das áreas mais instáveis para o interior das estáveis.

Posteriormente aos eventos tectônicos (e os reflexos) são reconhecidas fases importantes de tafrogênese, de forma diacrônica, do Mesoproterozóico mais superior para o início do Neoproterozóico (Periodo Toniano), a qual afetou tanto as áreas cratônicas como as faixas móveis do ciclo precedente. Estes dominios extensionais possuem registros geológicos (estruturas e geraçăo de rochas) por todo o supercontinente previamente formado (Rodinia), compondo assim um quadro tectônico com caracteristicas de fenômenos de fissão.

\footnotetext{
'Departamento de Geologia Geral, Instituto de Geocièncias/USP, São Paulo, Brasil.

${ }^{2}$ Instituto de Geociencias, Universidade de Brasilia, Brasilia, Brasil.

${ }^{3}$ Escola de Minas, Universidade Federal de Ouro Preto, Ouro Preto, Brasil
} 
Para as províncias estruturais do Neoproterozóico (ditas do Brasiliano), estes processos extensionais tiveram papel decisivo, como fase inaugural de novo ciclo wilsoniano. Com eles foram estabelecidos os primeiros traços estruturais, em termos de principais dominios sedimentares (bacias) e áreas fontes (altos tectônicos).

\section{ABSTRACT}

Evidence for the worldwide Grenville orogenic collage in South America has usually been pointed out throughout the basement of the Andean Chain, from Colombia to northwest Argentina, and in the Brasil-Bolivia border region (southwest of the Amazonian Craton).

New geological and geochronological data as well as a review on preexisting data, some of them from unpublished theses, demonstrate for the interior of our continent the occurrence of collisional and subordinate events (in Goiás-Tocantins massif, in the central part of Bahia-Minas Gerais states) during the same span of time (Ectasian Period, ca.1300 Ma) of the Mesoproterozoic Era.

The preferential, but not exclusive, sites for these events of plate and subplate interactions were those rifts and basin developed during a previous processes of taphrogenesis, very typical of the Statherian Period of the Paleoproterozoic Era (1800-1600 Ma).

The Mesoproterozoic (Ectasian) orogenic processes, which had preliminarly been designated - with many doubts- as "Uruaçuano" (Central Brazil) and "Espinhaço" (Central Bahia-Minas Gerais) are now being recognized as part of a broad compressional regime, due to the convergent interaction of plates and subplates, responsible for both building fold belts and reworking basement rocks. A striking post-orogenic phase of erosion is also recognized, with the development of widespread denudation events from the end of the Mesoproterozoic to Neoproterozoic times.

These orogenic processes are from now on being postulated as equivalent to those of the Grenville collage (North American continent), and accordingly, they are being recognized as part (in the interior of South America) of the worldwide phenomena of agglutination of continental masses that have formed Rodinia supercontinent. At the same time, subordinate activation processes may also be identified affecting marginal and interior zones of cratonic blocks, such as shearing, tilting, thermal and isotopic rejuvenation, and so on (at the same range of ages of the orogenic processes), which were reflex reaction to the vigorous tectonic of interaction of continental plates.

Succeeding the orogenic events, with their general processes of fusion of continental masses, widespread phase of taphrogenesis then took place, which have been identified (1100-950 Ma) throughout both previous cratonic areas and Ectasian fold belts themselves.

These extensional domains display a series of coeval geological records (generation of rocks and strucutural features) all over the just-agllutinated supercontinent of Rodinia, and so presenting general characteristics of fission phenomena.

Specially for the Neoproterozoic structural provinces (so-called Brasiliano), these extensional processes played an important and decisive role as inaugural phases of a new global tectonic cycle, for they defined most of the main depositional sites (basin-forming tectonics) and structural highs (source-areas).

\section{INTRODUÇÃO}

O recente conceito e a ampla aceitação do supercontinente Rodinia, na passagem Mesoproterozóico-Neoproterozóico (vide Hoffman, 1991, entre outros) e como fecho da Colagem Grenville trazem implicações importantes para o contexto do Pré-Cambriano da América do Sul. Torna-se necessária imediata reavaliação dos nossos dados geológicos e geocronológicos para que $a$ assunção deste esquema global ( $e$, de certa forma avassalador) não seja feito de forma compulsória, a reboque de modismos e de ilações de pesquisadores à distância, sem conhecimento dos nossos fatos.

A primeira dificuldade que enfrentamos é a "marca" das orogêneses me- 
soproterozóicas no nosso continente, quase sempre de registro não conspícuo e de certas sutilezas, por características próprias e pelos muitos tipos de sobreposições impostas. E, ainda, por conta de outras deficiências nossas de metodologias de análise.

Os registros estruturais e isotópicos destas orogenias e terrenos (Fig. 1) da parte superior do Mesoproterozóico

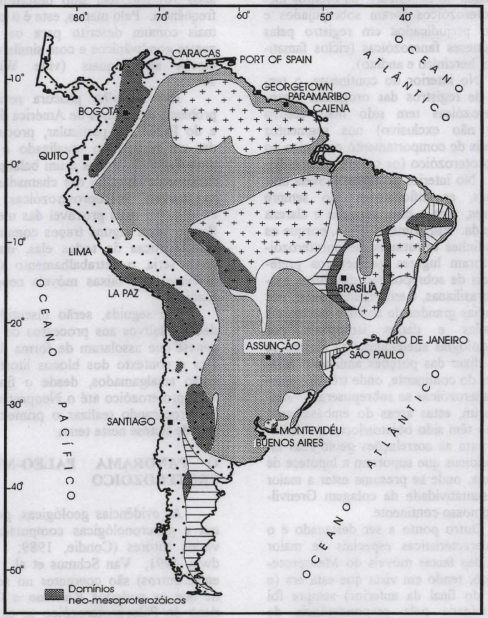

Figura 1 - Esboço geológico-geotectônico simplificado da América do Sul apenas para situar as ocorrências - afloramentos conjuntos ou dispersos, em subsuperficie, contextos retrabalhados - de orogenias e processos tectogênicos neo-mesoproterozóicos a e0-neoproterozóicos ("grenvillianos"). Estas ocorrências estăo exageradas em área por razōes expositivas. Diversas fontes (mencionadas nas Referências), modificadas livremente pelos autores. 
foram realmente bastante obnubilados por processos do Neoproterozóico, ou do Ciclo Brasiliano, mais abrangentes em área (e tempo) e, em geral, mais intensos por todo o continente. $\mathrm{Na}$ borda ocidental do continente, os eventos mesoproterozóicos foram sobrepujados e muito prejudicados em registro pelas orogêneses fanerozóicas (ciclos famatiniano, hercínico e andino).

No interior do continente, o resgate de registros das orogenias mesoproterozóicas tem sido mais efetivo (mas não exclusivo) nos segmentos crustais de comportamento cratônico no Neoproterozóico (os crátons sinbrasilianos). No interior de faixas móveis brasilianas, as dificuldades são sempre maiores, sem a discriminação e clareza desejada. Em primeiro plano, porque os sítios/linhas estruturais mesoproterozói$\cos$ foram lugares geométricos preferenciais de sobreposição das faixas móveis brasilianas, e em segundo lugar, por carências grandes de análises estruturais refinadas e dados isotópicos por metodologias adequadas. $\mathrm{O}$ mesmo se pode dizer das porçōes andinas e adjacentes do continente, onde três orogêneses fanerozóicas se sobrepuseram. Ainda assim, estas áreas do embasamento andino têm sido objetos/locais preferenciais para as correlações geológicas internacionais que suportam a hipótese de Rodínia, onde se presume estar a maior representatividade da colagem Grenville, em nosso continente.

Outro ponto a ser destacado é o das características especiais de maior parte das faixas móveis do Mesoproterozóico, tendo em vista que esta era (e parte do final da anterior) sempre foi discriminada pela preponderância de geocracias e processos intracratônicos. Em geral, excluindo-se Grenville e suas continuidades reais e prováveis, as demais faixas móveis mesoproterozóicas carecem tratamento em separado. Não são conhecidos muitos vestígios de oceanos e braços de oceano consumidos, o vigor das convergências parece ter sido reduzido, de forma que os orógenos clássicos da literatura "plaquista" (modelos clássicos norte-americanos dos anos 70) não têm sido descritos com freqüência. Pelo menos, este é o cenário mais comum descrito para os continentes gondwânicos e com similares nos blocos setentrionais (vide Windley, 1995).

Este trabalho procura revisar o problema em termos de América do Sul, e do Brasil em particular, procurando dar um tratamento atualizado e fazer uma discussão franca e um balanço dos dados e da situação das chamadas "faixas móveis" mesoproterozóicas, e do ciclo global mais provável das mesmas. Parece haver alguns traços comuns nas características de todas elas, um dos quais seria o retrabalhamento (quase unânime) por faixas móveis neoproterozóicas.

Em seguida, serão discutidos os dados relativos aos processos de tafrogênese que assolaram de forma diacrônica o contexto dos blocos litosféricas então amalgamados, desde o final do Mesoproterozóico até o Neoproterozói$\mathrm{Co}$, procurando realizar o primeiro ensaio de síntese neste tema.

\section{O PANORAMA PALEO-MESO- PROTEROZÓICO}

As evidências geológicas, geofisicas e geocronológicas computadas de vários autores (Condie, 1989; Goodwin, 1991; Van Schmus et al., 1993, entre outros) são coerentes no sentido de que os periodos Riaciano e Orosiriano do Paleoproterozóico se caracterizaram por processos de aglutinação de massas crustais continentais, tendo sido então fechados muitos oceanos e outros ambientes deposicionais conexos. Estas orogenias e colagens orogênicas (Wopmay, Penokeana, Makkovic, 
Ketlidiana, Sueco-Fennides, Stanovoiana, Eburneana-Transamazônica, Barramundi, etc.) têm excelente e extensiva representação mundial, inclusive no nosso continente, mesmo que aqui tenha sido sempre assinalada e designada de forma simplista ("Ciclo Transamazônico", "Orogênese Transamazônica", etc.). Esta conjunção de eventos orogenéticos, esta colagem ou dinastia, consubstanciou grande predomínio de massas continentais que teriam se tornado estáveis já na parte mais superior do $\mathrm{Pa}$ leoproterozóico, desde o início do período Estateriano (1,8-1,6 Ga).

Esta (ou estas) massa continental foi submetida posteriormente, por várias causas (Brito Neves et al., 1995), a processos extensionais, tafrogenéticos por excelência no período Estateriano (1800-1600 Ma), que deixou registros magmáticos, sedimentares, estruturais, etc. da Amazônia mais setentrional ao nordeste da Argentina.

Em termos de América do Sul, a única exceção com dados concretos a este cenário predominantemente cratogenético é o da Faixa Móvel Rio Negro-Juruena (Parguaza), que se estende da Venezuela ao Paraguai (sul do Rio Apa), onde há evidências de processos de convergência e subducção (Tassinari et al., 1995; Dall'Agnol et al., 1987), ao longo do Estateriano. Uma continuidade desta faixa no atual continente norte-americano (faixas "Inner Accretionary" e "Outer Tectonic", Van Schmus et al, 1993) é possivel e tem sido defendida por diversos autores como Sadowski \& Bettencourt (1996), sucedendo a primeira comparação entre estes dois continentes, feita já por Kroonenberg (1982).

Ainda incipientemente conhecida, devido à sua posição em região de floresta tropical e muitas coberturas mesoproterozóicas, há dados isotópicos indicativos de que esta faixa móvel se desenvolveu a partir de um substrato de idade orosiriana (Tassinari et al., 1995). A presença desta faixa, dentro de um contexto de bloco estável para o Ciclo Brasiliano (Cráton Amazônico) ratifica as observações já feitas na introdução, com um dado a mais a ser considerado: suas linhas estruturais (NNW-SSE) são ortogonais às direções brasilianas (da Faixa Paraguai-Araguaia). Esta posição, no nosso entender, foi que possibilitou a preservação (não regeneração) da faixa móvel, muito pouco ou não afetada pelos processos brasilianos sobrepostos. As relações geológicas entre esta faixa $(1,75-1,5 \mathrm{Ga})$ e a tafrogênese estateriana que lhe é praticamente contemporânea não são conhecidas ainda, mas devem ser bastante estreitas e de provável cogeneticidade.

Outra área que necessita discriminação é aquela longitudinal a oeste dos grandes complexos máfico-ultramáficos de Goiás e Tocantins, que inclui as assembléias vulcano-sedimentares de afinidade oceânica (Marini et al., 1984; Winge, 1995) de Juscelândia, Indaianópolis e Palmeirópolis, entre outras. Estas unidades podem ter sido geradas pela evolução da Tafrogênese Estateriana (mas podem ser mais antigas, orosirianas, faltam dados cronológicos decisivos), constituindo, assim, um ambiente tectônico especial, antes da convergência e ampla consolidação mesoproterozóica a ser discutida (ou seja, antes de $1,3 \mathrm{Ga}$ ).

Nestes termos, ainda assim, o panorama do final do Paleoproterozóico, e do início do Mesoproterozóico (este principalmente, com a consolidação de Rio Negro-Juruena), em $1600 \mathrm{Ma}$ são reconhecidamente estágios com predomínio de massas continentais (geocrático), onde as atividades intracratônicas foram preponderantes, em cenários de bacias (sinéclises, grábens, aulacógenos, trapas vulcano-sedimentares, etc.) criados pela tafrogênese estateriana e subsequientes. 


\section{OROGENIAS E OUTRAS ÁREAS MESOPROTEROZÓICAS}

Como já evidenciado, a identificação de processos de interação de placas no Mesoproterozóico é problemática, pela natureza e posição dos registros e/ou qualidade dos dados disponiveis. Neste contexto, reconhecendo estas dificuldades, vão ser destacadas:

a) $\mathrm{Na}$ porção sul-ocidental do Cráton Amazônico, em território boliviano e na zona lindeira com o Brasil, situa-se a mais completa e bem documentada exceção ao quadro acima exposto. A faixa San Ignácio (1500-1280 Ma), que constitui o "Cráton"/Bloco Paragua, de substrato orosiriano (Lomas Maneche $=$ Transamazônico) e a faixa SunsásAguapei (1280-950 Ma) que the é circunscrita, estão bem estabelecidas e mapeadas na escala $1 / 100.000$, desde 0 trabalho de Litherland et al. (1986).

Estas faixas, circunscritas por domínios brasilianos (faixas/ramos Araguaia-Tucavaca-Paraguai), não serão discutidas nesta oportunidade em face à sua caracterização prévia ser conhecida e de muito boa qualificação, pelo trabatho de Litherland et al., acima mencionado, e outros subseqüentes.

b) Por toda a zona de embasamento da faixa andina, em seus três segmentos longitudinais, têm sido apontadas ocorrências de contextos litoestruturais mesoproterozóicos ("zonas", "faixas", "áreas", etc., que serão discutidas adiante). Ora estas ocorrências são apontadas como correlacionáveis aos contextos de San Ignácio e SunsásAguapei, como no caso dos Andes Setentrionais. Ora estas ocorrências são apontadas como um todo como representativas da continuidade do cinturão Grenville (vide Sadowski \& Bettencourt, 1996, entre outros), quando da justaposição do bloco Laurentia a oeste do bloco de Gondwana (final do Neoproterozóico e início do Fanerozóico).
Neste caso, a faixa Grenville seria a responsável-mór pelo amalgamento de blocos e aglutinação de Rodínia.

Uma breve discussão neste tema deve ser desenvolvida, reiterando a qualidade precária dos dados, na maior parte das vezes, em termos de registros geológicos e de dados isotópicos, estes escassos e incompletos, se considerarmos a ordem de grandeza da hipótese sobre eles calcadas.

c) Em várias áreas e zonas afetadas e em muitas bacias geradas com a tafrogênese do estateriano, em todo o continente, há evidências de interação de blocos litosféricos (microplacas, "subplacas") bem posterior, na parte média do Mesoproterozóico (período Ectasiano, $1400-1200 \mathrm{Ma}$ ), praticamente contemporâneos aos eventos principais da orogenia San Ignácio $( \pm 1300 \mathrm{Ma})$. É digno de nota que os eventos precursores do Ciclo San Ignácio (extensionais) são também do período Estateriano (no caso, entre 1800 e $1600 \mathrm{Ma}$ ). Este fato complementa e consigna assim esta dualidade que vai se caracterizando por todo o continente: extensão/divergência preponderantes no Estateriano, interação de blocos/convergência no Ectasiano.

Cabe acrescentar que nem todos os produtos/associações geradas no Estateriano foram deformados e envolvidos neste processo de interação do Ectasiano. Alguns só vieram a ser deformados em orogêneses neoproterozóicas, outros permanecem "não" deformados até o presente.

São considerados partes desta consolidação mesoproterozóica os terrenos situados na parte central e centroocidental do "maciço" Goiás-Tocantins, longitudinais a oeste aos grandes complexos máfico-ultramáficos. Para retornar a este tema, deve-se redefinir a "Orogênese Uruaçuana", que foi a primeira designação (a ser discutida) evocada para processos afins, em fase muito 
preliminar do conhecimento. Também são relacionadas neste processo evolutivo as estruturas do centro da Bahia e sul-sudeste de Minas Gerais, de há muito referidas como expressão da "Orogenia Espinhaço" ou "Sistema de Dobramentos Espinhaço-Chapada Diamantina Ocidental" (Cordani \& Brito Neves, 1978)

É possível que outras faixas/áreas com expressão territorial semelhante venham a ser identificadas em futuro (como o caso da Faixa Rio Grande, parte do Grupo Andrelândia, como defendido por alguns autores), mas decisivamente faltam dados.

d) Os processos interativos do tipo continente-continente, com ou sem subdução envolvida, tiveram ampla repercussão além destes sítios orogenéticos então gerados, em margens de Segmentos litosféricos, consignando vários eventos geológicos dispersos, sempre colocados sob a égide de processos de "reativação" ou rejuvenescimento, paraplataformais, etc. de forma passageira, e cujos dados somente agora começam encaixar numa interpretação coerente.

No Cráton Amazônico (eventos "K'mudku-Nickeriano-Orinoquense", ou "Jari-Falsino" e/ou "Rondoniense", de diversos autores) e no Cráton do São Francisco (designações pouco usuais, informais) vários processos de tectônica cratogênica têm sido descritos e profusamente nomeados, todos eles dentro do intervalo de tempo Ectasiano. A conexão de tais eventos de nível crustal raso a intermediário no interior de placas litosféricas continentais com os processos orogenéticos sincrônicos ocorrentes nas margens destas placas (Hsü, 1982; Xingyuan, 1988) é hoje fato de rotina da geotectônica, com muitos exemplos a nivel mundial, e postulado complementar da rigidez da litosfera.

e) A presença de outras edificaçōes orogenéticas mesoproterozóicas semelhantes a estas acima mencionadas é uma possibilidade em aberto na infraestrutura de algumas faixas brasilianas, e com algumas indicações prováveis (na Borborema, no Ribeira, etc.). Mesmo porque, as faixas ditas uruaçuanas (esta de forma integral) e a do Espinhaço (parcialmente) são na verdade exposições privilegiadas da infra-estrutura de faixas móveis brasilianas, reestruturadas a diversos níveis, e só preservadas por caprichos da posição tectônica no Neoproterozóico (frações mais estáveis do antepaís, externides em geral, jogo de escamas tectônicas, etc.).

$\mathrm{Na}$ província Borborema, ao longo das faixas Piancó-Alto Brigida e $\mathrm{Pa}$ jeú-Paraíba, têm sido identificadas litologias e estruturas que evidenciam um processo tectogenético importante (ortognaisses principalmente, metamorfitos, etc.) de idade semelhante àquela de Sunsás-Aguapeí. Estes processos mesoneoproterozóicos (de forma inquestionável) foram provisoriamente designados como "Cariris Velhos", por Campos Neto et al. (1994) e Brito Neves et al. (1995). O estudo do significado real (subdução e colisão têm sido indicados com dados concretos) e da extensão em área do "Cariris Velhos" constitui uma etapa importante de pesquisas, ora em desenvolvimento na Borborema.

\section{O SUBSTRATO PRÉ-CAMBRIANO DOS ANDES}

De uma análise criteriosa na vasta bibliografia e nos dados geológicos e geocronológicos dos diversos tipos de exposições (e circunstâncias tectônicas de ocorrências) de terrenos pré-Cambrianos da faixa andina chega-se a pontos de conclusão tácita e poucas exceções, que devem ser adiantados:

a) Há um grau pouco satisfatório e irregular no conhecimento geológico geral, sendo dificil vislumbrar uma ambiência geotectônica comum para todos eles e a sua correlação (em primeiro lu- 
gar) com aquelas exposições mais ocidentais das áreas de escudo da América do Sul.

b) Constata-se uma série de valores de idade de 1300 a $900 \mathrm{Ma}$, por diversas metodologias, extraídas de trabalhos de nivel e objetivos os mais diversos (predominam trabalhos ao nível de estudos de reconhecimento). Destacamse alguns dados mais antigos locais (poucos valores paleoproterozóicos) e outros mais jovens sobrepostos, neoproterozóicos e fanerozóicos.

c) Há uma tendência geral, entre os autores, de aludir estes contextos lito-estruturais como expressão da Colagem ou Orogenia Grenville, falando em correlação e extensão desse desenvolvimento para a América do Sul. Se estas proposições são corretas e sem contra-indicações, não pode ser confirmado ainda. Mas, em todas elas há forte cunho especulativo (este muitas vezes mais expressivo que os dados geológi$\cos$ e geofísicos em geral) e estão longe de serem preenchidos os requisitos clássicos de correlação em geologia.

\section{Andes Setentrionais}

Nos Andes Setentrionais, onde há várias e boas exposições, do Pacífico à fronteira brasileira, ocorrem rochas de alto grau, migmatitos, granulitos (e granito rapakivi), para os quais Kroonenberg (1982), em excelente síntese, propôs a definição integrada de cinturão granulitico Garzon-Santa Marta (Fig. 2), circundando a borda norte-ocidental do bloco brasileiro. O mesmo autor, coligindo os dados geocronológicos preexistentes, propôs para este desenvolvimento um evento orogenético de 1300 $1200 \mathrm{Ga}$, e equivalente ao Grenville, no continente norte-americano. Várias unidades litológicas de alto grau (granulitos de diversas composições e estruturas) e granitóides sintectônicos (ortognaisses) foram descritos por este autor, inclusive fora do cinturão por ele proposto.
Além disso, Kroonenberg (1982) também apontou uma relação destes eventos orogenéticos com aqueles paraplataformais, comuns em todo o Escudo da Guianas, como o chamado evento Nickerie de Priem et al. (1971).

Suarez (1990) enfatizou o papel de duas importantes suturas nesta porção andina, separando três diferentes terrenos. A primeira, o "sistema de sutura Romeiral", balizando a Cordilheira Ocidental e parte da Cordilheira Central, separando o terreno de evolução fanerozóica (WP= Western Province). A leste desta sutura fica o cinturão granulítico Garzon-Santa Marta, constituindo um terreno da colagem grenvilliana, que é separado mais a leste da $\mathrm{Pla}$ taforma Sul-Americana (com rochas de idade Parguazense-Rio Negro Juruena) pela zona de sutura e eventos magmáticos "Borde Llanero", da Venezuela e Colômbia (vide Fig. 2).

Apesar de serem estas versões arrojadas, de sintese, elas são, ao nosso ver, aquelas melhor subsidiadas em dados concretos.

\section{Andes Centrais e Meridionais}

No Peru, o bloco de Arequipa, ou "Cráton Arequipa-Antofalla", que inclui parte do noroeste argentino (Ramos, 1988), tem muitas abordagens anteriores (Dalmayrac et al., 1977; Cobbing et al., 1977 , etc.), devido à sua invulgar posição geológica, sua extensão, e o seu papel nos ciclos do Proterozóico e Fanerozóico.

São conhecidas rochas de alto grau, de idade paleoproterozóica (Evento "Mollendo", $1950 \mathrm{Ma}$ ), que parecem predominantes nos traços estruturais principais, no Peru, com outros dados isotópicos de eventos sobrepostos no final do Proterozóico ("Ático") e no Fanerozóico ("Marcona").

As ocorrências de Belen, Choja Limón Verde, Antofalla e Mejillones (Fig. 3), abordadas por diversos autores, 


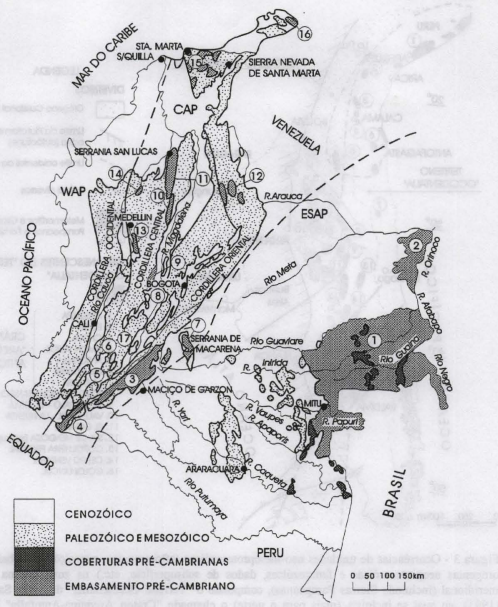

Figura 2 - Esquema dos terrenos nos Andes Setentrionais, especificando as ocorrências de substratos Pré-Cambrianos, consoante Kroonenberg (1982) e Suarez (1990).

a) Provincias Estruturais (terrenos):

ESAP = Escudo das Guianas, Plataforma Sul Americana, Faixa paleoproterozóica Rio Negro-Juruena; $\mathrm{CAP}=$ Provincia Andina Central, terreno alóctone, provável procedente do bloco norte-americano ("grenvilliano"); WAP = Terreno do pacifico ocidental, de acresção pós-Jurássico.

b) Esposições do embasamento:

1 e 2 - Complexo Mitú e granitos Parguazenses (ESAP); 3 - Maciço Garzon; 4 - Alisales/Guamués; 5 Serrania de las Minas; 6 - La Plata; 7 - Macarena; 8 - Payandé; 9 - Lérida Venadillo; 10 - Puerto Berrio; 11 - San Lucas; 12 - Bucamaranga; 13 - Caldas La Miel; 14 - Puqui; 15 - Sierra Nevada de Santa Marta; 16 - Guajira; 17 - Mendaco/Ambeima. 


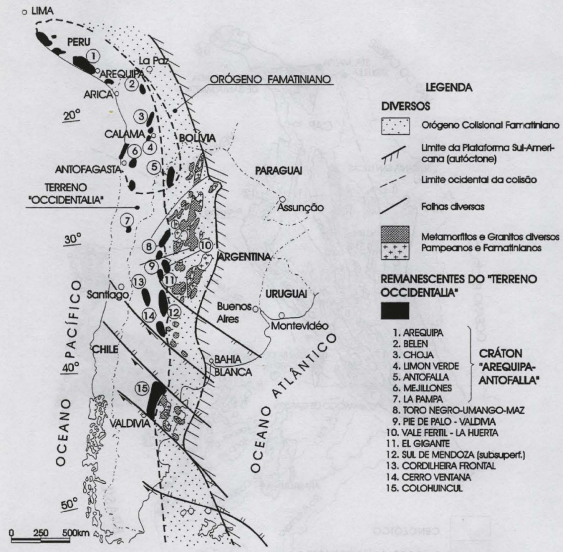

Figura 3 - Ocorrências de unidades neo-mesoproterozóicas (afloramentos, exposições retrabalhadas por orogenias neoproterozóicas e fanerozóicas, dados de subsuperficie, etc.) na zona andina central e meridional (incluindo Sierras Pampeanas), compondo o "Terreno Occidentalia" de Dalla Salda et al., (1993), no qual se incluiria (mais para o norte) o chamado "Cráton Arequipa-Antofalla" de Ramos (1988).

Obs. No bloco Arequipa há ocorrências de rochas paleoproterozóicas e mais antigas também. Comsoante Ramos et al. (1995), as rochas "grenvillianas" se estendem para leste, na Argentina, pelo menos até as imediaçōes de Córdoba.

estão aqui consideradas e figuradas no contexto Cráton Arequipa-Antofalla, sinbrasiliano, de Ramos (1988).

Dalla Salda et al. (1993) confirmam a presença de diversas rochas de médio a alto grau metamórfico de idade mesoproterozóica no contexto deste embasamento, variando de $1300 \mathrm{Ma}$ (aí se incluindo algumas poucas determinações U-Pb em zircão) até cerca de 900 $\mathrm{Ma}$ (a maioria pelo método $\mathrm{K}-\mathrm{Ar}$ em minerais). Como pode se observar na Figu- 
ra 3 , estes autores colocam estas exposições, em seu maior número dentro de um bloco crustal, o "Terreno Occidentalia", que seria uma porção do Bloco Laurentia, a oeste da faixa FamatinianaApalachiana, eofanerozóica (decorrente do fechamento do ramo sul do Oceano Iapetus), balizada a leste pela plataforma Sul-Americana (na sua versão para o Paleozóico Inferior). Ou seja, o bloco em questão seria uma fração litosférica de Laurentia deixada na América do Sul, desde a separação, pós-Gondwana, dos continentes (em torno de 440 Ma atrás).

Fundados nas hipóteses iniciais de Moores (1991, "SWEAT connection") e Dalziel (1991), vários autores consideram este segmento crustal a oeste do nosso atual continente como a continuidade natural do Sistema Grenville, que teria sido a faixa móvel que balizou esta pretérita e episódica ligaçăo Laurentia (América do Norte + Groenlândia)Gondwana Ocidental. A leste do terreno mencionado ter-se-ia desenvolvido a orogênese colisional Famantiniana (Tacônica) no Paleozóico Inferior (Siluriano-Eo-Ordoviciano, 480-440 Ma), na zona peri-Pacífico da América do Sul, com registros desde o Peru até a Patagônia.

O Prof. Victor Ramos e co-autores, em diversos trabalhos nesta década, estendem a importância das rochas formadas na orogênese Grenville às porções de embasamento mais orientais, fundado inclusive em alguns dados de sondagens: das Sierras Pampeanas (como já feito por Dalla Salda et al, 1993) até as imediações de Córdoba, e para sul até as imediações do Rio Colorado, ou seja consubstanciando grande parte do o embasamento do chamado "Cráton Pampia". Baseado em alguns dados recentes, e em outras características geoquímicas e petrológicas, Vujovich \& Ramos (1993) propõ̃em que o amalgamento de uma série de arcos de ilhas mesoproterozóicos deve ter sido respon- sável pela consolidação do embasamento do Cráton Pampia, em torno de 1150 a $1066 \mathrm{Ma}$. E, assim, este cráton deve ser visto como fração, uma fração a mais derivada da fragmentação do Rodínia.

\section{A FAIXA URUAÇUANA}

\section{Breve Histórico}

A introdução do conceito de "Ciclo Uruaçuano" (ciclo tectônico, tectônico-magmático, região de dobramentos, etc.) foi feita por Almeida, em 1968, no centro-oeste brasileiro, enfocando naquela oportunidade o domínio do "maciço" central de Goiás como estrutura pré-Uruaçuana parcialmente remobilizada, e o dominio imediatamente a leste deste como "complexos dobrados uruaçuanos" ("zona eugeossinclinal"). Neste caso, referindo-se aos complexos vulcano-sedimentares que Ebert (1957) destacara sob a égide de "estruturas araxaides". Segundo Almeida, sucederamse episódios tecto-orogenéticos, acompanhados de metamorfismo regional e regeneração de estruturas antigas no centro-oeste brasileiro, por toda a zona de separação dos crátons "Guaporé" (Amazônico) e São Francisco.

Em 1969 (apresentação oral), e em 1971, Almeida propôs uma divisão tríplice para o Pré-Cambriano da América do Sul, utilizando-se de seus trabalhos anteriores e dos dados radiométricos até então catalogados. Definiu dentro do Pré-Cambriano Superior os ciclos Espinhaço - 1800-1300 Ma - Uruaçuano - 1300-900 Ma - e Brasiliano - 900-570 $\mathrm{Ma}$.

Em 1970, Hasui \& Almeida, baseando-se no contingente disponivel de determinações radiométricas (K-Ar mais que $\mathrm{Rb}-\mathrm{Sr}$ ) e em novos mapas geológicos surgidos (Projeto Brasília, Projeto Araguaia), ratificaram o conceito de Almeida (1968). Além disso, tendo alguns dados do Grupo Araxá (que tinha outra 
conotação a esta época) como base, postularam os valores de $1400 \mathrm{Ma}$ a 980 Ma para o Ciclo Uruaçuano. Neste trabalho do Boletim da SBG (vol. 19, $\mathrm{n}^{\circ}$ $1: 7-26$ ), que por muito tempo foi uma espécie de documento oficial do Uruaçuano neste continente, foi apresentada uma "isócrona" de referência de 1400 $\mathrm{Ma}$, que em realidade reunia dados de contextos litológicos bastante diversos (Grupo Araxá, Cráton Amazônico, Maciço Central, etc.), e que por muito tempo foi o "referencial" (absolutamente inadequado) a ser mencionado para o "Uruaçuano".

Herz, em 1970, condensou excelente sintese dos dados radiométricos do Quadrilátero Ferrifero, mostrando em histograma cinco eventos termais importantes (entre 2700 e $500 \mathrm{Ma}$ ). Propôs uma cronologia de evolução para o Quadrilátero (que considerou uma "noisy area", em termos radiométricos) de notável procedência, onde destacou os valores de idades ( $\mathrm{Rb}-\mathrm{Sr}$ e $\mathrm{K}-\mathrm{Ar}$ ) de 1350 e $1000 \mathrm{Ma}$ pela primeira vez, dando origem assim a algumas inadequadas designações informais (como a de Ciclo "Minas"), de forma involuntária.

Em 1972, na Notícia Explicativa da Carta Tectônica do Brasil, Ferreira utilizou (e oficializou) as designações "regiōes (e ciclo) de dobramentos "Minas-Uruaçuanos", 1300-900 Ma para o leste, sul e oeste do Cráton do São Francisco, numa tentativa (não muito feliz, nem apropriada) de adaptar os dados anteriores de Herz àqueles de Hasui \& Almeida (1970). Ainda neste trabalho, apontou para o Cráton Amazônico extensas manifestaçōes magmáticas de plataforma durante este ciclo recém redefinido (os eventos de "reativação" já comentados, Nickerianos, etc.).

Em 1973, em livro de circulação internacional, Almeida e colaboradores reiteraram o conceito de Ciclo Geotectônico Uruaçuano, entre 1400 e $900 \mathrm{Ma}$, na parte média do "Pré-Cambriano Su- perior", cujas principais entidades geotectônicas seriam os "Minas Folded belt" e o "Araxá Folded Belt". Estas constatações (hoje não mais aceitáveis) têm de ser evocadas e compreendidas somente para o estágio de conhecimento da época.

Ainda, em 1976, Hasui \& Almeida definiram a Faixa Uruaçu circundando a borda ocidental do Cráton do São Francisco, enfeixando os grupos Araxá e Andrelândia, por suas características lito-estruturais e de metamorfismo, tendo ela sido retrabalhada posteriormente no Ciclo Brasiliano. Desfizeram então a pretensa "correlação" Uruaçuano-Minas de Ferreira (1972), e de alguns outros seguidores, passando a considerar (corretamente) o Supergrupo Minas de idade bem mais antiga, ao mesmo tempo que reiteraram a possibilidade da correlação dos ciclos Uruaçuano e Espinhaço.

Em todas estas menções anteriores, a geologia caminhou mais a reboque das determinações geocronológicas, sempre com grande preocupação em evidência para com o significado destes dados da parte superior do Mesoproterozóico. E a partir deste tipo de consolidação do conceito, este "ciclo" em epigrafe foi levado a diferentes partes do continente, ou foi evocado de diferentes situações geológicas.

Excelente retrato e sintese destas preocupação e pendência indissociável, foi o esboço apresentado por Tassinari e outros em 1986, calcados numa resenha de todos os dados radiométricos disponíveis no centro-oeste, onde se verifica a presença de "dados uruaçuanos" por toda região central do Brasil, do Rio Araguaia para leste até o paralelo $46^{\circ} \mathrm{W}$ (rochas do embasamento, complexos intrusivos, supracrustais, etc.).

Qual o significado real desses dados e desse Ciclo?

No nosso entendimento, esses dados são válidos e eles representam os 
amplos processos de convergência do período Ectasiano, modificando radicalmente os sítios deposicionais, estruturando as supracrustais e complexos igneos gerados na tafrogênese estateriana, com repercussão nas rochas do embasamento, de consolidação no Arqueano e no Paleoproterozóico (Transamazônico, Faixa Ticunzal e correlatas). E, desta forma, este ciclo estaria desvinculado da deformação dos Grupos Araxá (muito provavelmente só veio a ocorrer no Neoproterozóico, com o Ciclo Brasiliano) e do Grupo Andrelândia (cuja deformação pré-Brasiliano, defendida por alguns autores, é ao nosso ver altamente duvidosa ainda).

Este processo de interação de placas e subplacas (à altura dos meridianos $49^{\circ}$ e $50^{\circ}$ ) teve repercussão lateral ampla, com extensão e processos correlatos bem mais a leste no dominio do Espinhaço e da Chapada Diamantina Ocidental, cujos primórdios de segmentação litosférica foram igualmente promovidos na tafrogênese estateriana. A expectativa de um processo orogênico simples e bem definido no tempo, dentro dos modelos habituais da bibliografia (exigida por alguns autores), não se coaduna com os dados geológicos e geocronológicos disponíveis nestas regiōes em consideração. $\mathrm{E}$ isto não é necessário (vide Hsü, 1982), devendo relembrar que houve retomada (e modificaçōes impostas) destas zonas de interaração no Ciclo Brasiliano, no Neoproterozóico

\section{Características gerais}

Os traços da zona principal da orogenia Uruaçuana já foram de certa forma apontado por Almeida (1981), dentro de outra conotação, com os cinturões "Ceres" e "Alfenas" (este como a continuidade para sudeste, para a Faixa do Alto Rio Grande, que é problemática), que seriam a expressão dos limites do seu "Cráton do Paramirim", um Seg- mento arqueano, pós-Ciclo Jequié, diferenciado da litosfera.

Como discutido acima, a representação lito-estratigráfica principal deste ciclo se faz com os contextos ígneos (complexos máfico-ultramáfico acamadados, granitos anorogênicos, vulcanismo de riftes), sedimentares (Arai-Serra da Mesa, Natividade e correlatos) gerados no período Estateriano. Há possibilidade de incluir neste conjunto as seqüências vulcano-sedimentares ocidentais (Juscelândia, Palmeirópolis e Indaianópolis (vide Marini et al., 1984) aos grandes maciços, mas elas podem ser de geração pouco mais antiga (pré-Estateriano). A Figura 4, extraída de Winge (1995), expressa esta possibilidade, com 0 início dos eventos de extensão no $\mathrm{Pa}$ leoproterozóico e o fechamento colisional e a obducção somente no Mesoproterozóico (1300 Ma). De um modo ou de outro, estas unidades e outras de embasamento, a leste e a oeste, foram fortemente envolvidas na deformação mesoproterozóica.

A tergiversação usual em torno da idade destes processos orogenéticos deformação, metamorfismo, encurtamento e espessamento crustal - se deve primeiro à falta de um estudo geocronológico objetivo, na escala de detalhe e com metodologias adequadas. Em segundo lugar (e de certa forma, em decorrência dessas demandas de dados) devido ao envolvimento subseqüente desta faixa e do seu embasamento nos eventos (distensionais, magmáticos, compressionais) do Ciclo Brasiliano, que foi bem mais abrangente em área, com desenvolvimentos complexos a oeste (arco magmático de Goiás, faixa Araguaia-Tucavaca-Paraguaia) e a leste (Faixa Brasília). Em outras palavras, a utilização e super-exploração de metodologias isotópicas de reconhecimento ( $\mathrm{Rb}-\mathrm{Sr}$ e $\mathrm{K}-\mathrm{Ar}$ ) em rochas não adequadas, ao lado da dispersão de valores de idades realmente promovida pelos even- 
1. Fases RIFTE CONTINENTAL E SUBSEQÜENTE (> $1.8 \mathrm{Ga})$

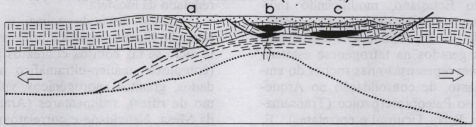

a. Bacia Araí - Serra da Mesa.

b. Complexos gabro-noríticos ("Santa Bárbara").

c. Complexos troctollto gabro-anortosíticos ("Sa. Malacacheta").

\section{Fase PROTO-OCEÂNICA A OCEÂNICA}

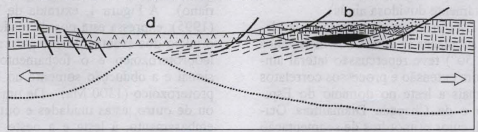

d. Seqüência vulcano-sedimentar ("Juscelândla").

b. Complexos gabro-anortosíticos.

3. Fase de CONVERGÊNCIA, colisão com obducçăo dos complexos máficos-ultramáficos. Duplicação crustal e granulitizaçāo $( \pm 1.3 \mathrm{Ga})$

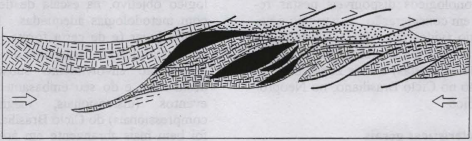

Figura 4 - As fases evolntivas para os terrenos paleoproterozóicos (Tafrogênese Estateriana) do Brasil Central e a sua deformação na orogenia "uruaçuana", modificado de Winge (1995).

tos do Brasiliano, têm conjuntamente tornado complexo o entendimento desta faixa uruaçuana.

São considerados subsídios essenciais para a proposição desta intera ção de placas no final do Mesoproterozóico: a posição tectônica na periferia de um segmento litosférico distinto ("placa" ou Cráton Paramirim), a expressão gravimétrica denotando espessa- 
mento crustal significativo (Lesquer et al., 1981: Haralyi \& Hasui, 1981; Hasui \& Haralyi, 1986), a imbricação tectônica de diferentes contextos de médio a alto grau de metamorfismo, a coerência de dados geocronológicos recentes (alguns inéditos) consignados, a serem discutidos. Além disto, Faria (1995), entre vários outros, demonstrou significativa discordância angular no topo o Grupo Araí, antecedendo a sedimentação do Grupo Paranoá (de idade entre 1300 e $1100 \mathrm{Ma}$ ), assumido como registro lito-estratigráfico precursor do ciclo subsequiente.

Os dados geocronológicos, obtidos no Complexo Barro Alto (granulitos félsicos predominantes, Figs. $5 \mathrm{a}$ e $5 \mathrm{~b}$ ) e na Sequêencia Juscelândia (biotita e hornblenda-gnaisses, Figs. $5 \mathrm{c}, 5 \mathrm{~d}$ e $5 \mathrm{e}$ ), constituem um conjunto coerente, e indicativo de forte re-homogeneização isotópica de $\mathrm{Sr}^{87}$, em níveis crustais profundos, em fácies anfibolito alto e granulito, consoante Fuck et al. (1989). Os valores de idades obtidos $(1266+17 \mathrm{e}$ $1330+67$ ), em diferentes afloramentos amostrados são mutuamente complementares e bastante significativos, envolvendo circunstâncias especiais nas quais as relações lineares gerais do sistema $\mathrm{Rb}-\mathrm{Sr}$ foram preservadas de forma muito boa (pequeno número de pontos analíticos foge aos alinhamentos). Trata-se de uma redistribuição muito regular dos isótopos de Sr durante o metamorfismo regional, após delongada residência crustal das rochas envolvidas, com uma sensivel elevação nos valores das razões iniciais. Estas isócronas caem no modelo 1 de Matheney et al. (1990), satisfazem várias premissas da interpretação do método de análise e o significado do valor da idade não deve ser fortuito.

$\mathrm{Na}$ borda oeste do Maciço Cana Brava (Sequêencia Palmeirópolis), Girardi et al. (1978) obtiveram uma isócrona de idade semelhante, em diferen- tes litologias (gnaisses, xistos, cálcio-silicáticas), $\mathrm{T}=1157+150 \mathrm{Ma}$ para uma razão inicial de apenas 0,704 . Recentemente, Correia (1994) obteve para rochas gabróicas frescas, cuidadosamente pré-selecionadas, do Maciço de Cana Brava a idade de $1350+35 \mathrm{Ma}(\mathrm{Ri}=$ 0,7168 ), interpretada como de metamorfismo regional, o que vem ratificar todos os valores acima discutidos, dentro da escala de abordagem.

Para as rochas metavulcânicas ácidas do Grupo Arai, Reis Neto \& Cordani (1984) obtiveram uma isócrona de referência de qualidade apenas razoável $(\mathrm{n}=8, \mathrm{Ri}=0,712)$ no valor de idade de $1140 \mathrm{Ma}$, em diagrama onde a sobreposição da influência de ciclos sobrepostos é notória, com vários pontos abaixo da reta principal computada, idade esta que pode ser considerada como afim dos dados acima expostos. Para os granitos de Serra da Mesa e Serra Dourada, a dispersão dos dados Rb-Sr é grande (alguns pontos acima da reta), e o valor de idade obtido (em torno de $1460 \mathrm{Ma}$ ) não contribui com nossa linha de argumentação, mas não a contradiz.

Somente na presente década, as determinações Sm-Nd começaram a contribuir ao problema. Primeiramente, Suita et al. (1994) com determinações $\mathrm{U}-\mathrm{Pb}$ reiteraram a idade do complexo de Barro Alto (1,73-1,72 Ga) e de seu metamorfismo no Ciclo Brasiliano (há cerca de $0,78 \mathrm{Ga}$ ). Uma outra determinação, em gabros pegmatíticos da Seqủência Serra da Malacacheta, considerado de um estágio tardio, apontou idade de 1,29-1,35 Ga nos interceptos superiores da concordia e valores de $0,77-0,82 \mathrm{Ga}$ para os interceptos inferiores. Estes valores de idade no Mesoproterozóico foram interpretados por Suita et al. como marcadores de uma fase extensional (e não de convergência e metamorfismo, como defendemos). Estes dados foram publicados em forma de resumo (a tese de doutoramento do autor senior não 

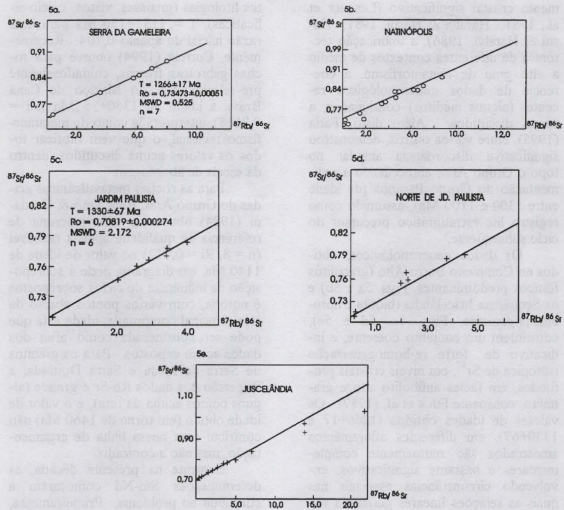

Figura 5 - Os diagramas isocrônicos obtidos por Fuck et al. (1989) no Maciço de Barro Alto e na sequência de Juscelândia .

5a. Serra da Gameleira, sudeste de Natinópolis, maciço de Barro Alto, granulitos félsicos (uma exceção apenas; isócrona "verdadeira").

5b. Amostras de diversas localidades, inclusive da Serra da Gameleira, a este e sudeste de Natinópolis, granulitos félsicos predominantes. A isócrona da Serra da Gameleira é colocada como referência, ajustando-se bem à maioria dos pontos analíticos.

5c. Gnaisses a biotita e hornblenda da Sequêencia Juscelândia, em Jardim Paulista (2 km ao norte), "isócrona verdadeira".

5d. Gnaisses e anfibolitos da Sequeência Juscelândia, $3 \mathrm{~km}$ ao norte de Jardim Panlista. A isócrona do sitio anterior é colocada como referência e ajusta-se bem à maioria dos pontos analíticos.

5e. Gnaisses e anfibolitos da Sequiência Juscelândia, coletados nas imediaçōes da cidade topônima. A isócrona de Jardim Paulista é colocada como referência.

circulou devidamente), aguardando-se muito da posterior apresentação por extenso dos resultados e conclusões.

Correia et al. (1996), prosseguin- do um contexto de detalhamento do maciço de Cana Brava, reiteraram a validade da isócrona $\mathrm{Rb}-\mathrm{Sr}$ (obtida por Correia, 1995) de idade 1350 (30 Ma 
para uma razão isotópica $\mathrm{Sr}^{87} / \mathrm{Sr}^{86}$ de $0,7168(0,0001$, considerada como de metamorfismo regional, comparando estes valores com aqueles obtidos por Fuck et al. (1989). Ainda no mesmo trabalho, utilizando o método Sm-Nd, concluíram que a intrusão e cristalização do corpo máfico-ultramáfico se processou no Paleoproterozóico (ca. $2,0 \mathrm{Ga}$ ) e que ele foi submetido a um processo metamórfico principal e deformação compressional em torno de $1,3 \mathrm{Ga}$, hávendo posterior reequilibrio metamórfico durante o Neoproterozóico (Ciclo Brasiliano), em torno de $0,77 \mathrm{Ga}$.

Consideramos, no cômputo geral dos dados, os dados acima discutidos geológicos e geocronológicos - que um processo orogenético, provavelmente de natureza colisional, teve lugar no Brasil Central na ordem de $1300 \mathrm{Ma}$, e que pode ser considerado contemporâneo (e de certa forma paralelos e conexos) dos demais processos de San Ignácio e Espinhaço-Chapada Diamantina, e complementar no que tange à consolidação/fusão de uma grande massa de áreas continentais. Para o norte (área de Natividade) os processos e reflexos desta interação tectônica parecem se amenizar bastante, de maneira semelhante ao que ocorreu para leste, para o lado do atual Cráton do São Francisco, a leste da Chapada Diamantina.

A designação de Orogenia Uruaçuana é evocada, ficando clara a conotação diferente (da designação original), em termos de origem, de área (em parte), materiais e agentes envolvidos no processo. A manutenção desta designação é para evitar a criação de novos termos, e em respeito ao que vislumbraram esta orogenia, e mais ainda para não fomentar complicaçōes dispensáveis na terminologia. Os presentes autores admitem que o reconhecimento desta orogenia, nos termos aqui propostos, não é de reconhecimento pleno, mas admitem também que isto é apenas questão de tempo e do surgimento de novos dados.

\section{SISTEMA DE DOBRAMENTOS ES- PINHACO - CHAPADA DIAMAN- TINA}

\section{Consideraçōes introdutórias}

Modernamente, faixas móveis são definidas como resultado dos processos interativos de placas ou segmentos litosféricos distintos. Nestes processos, todo o contexto de coberturas presentes no lugar geométrico da interação e adjacências será deformado, em diferentes niveis estruturais, sejam eles de afinidade continental (bacias IF, IS, MS, LL, Kingston et al., 1983) ou oceânica (bacias TA T, OSLL, OS), assim como frações expressivas dos respectivos substratos. Esta deformação, para dar vazão ao encurtamento crustal e litosférico, se propaga lateralmente, dos sítios principais da interação ao interior das placas litosféricas, na razão direta da magnitude e do tipo de interação (colisão é quase sempre o de maior intensidade) e da idade termal das unidades envolvidas, inclusive do embasamento das áreas vizinhas.

Nas bacias sedimentares, a deformação pode ocorrer por vários fatores: adjacências de zonas de interação, falhas transcorrentes, magmatismo intraplaca, processos extensionais sobrepostos, impactos extraterrestres, etc., numa ordem aproximada de freqüência e intensidades. Mas, em todos esses casos, o espessamento e encurtamento litosférico é de pouca monta e o embasamento é poupado, ou raramente ductilizado. Estas deformações caem sempre na égide de "idiomórfica" ou "descontínua", podendo ser classificadas (Kingston et al., 1983) desde muito fracas (locais, sem grandes efeitos) até muito fortes (reversão de bacias, estruturas em flor, rejuvenescimento do embasamento, etc.), consoante diferentes classes.

De forma que entre a faixa móvel 
(entre segmentos litosféricos) e a bacia sedimentar deformada (intraplaca) sempre haverá feições assemelhadas, e, em alguns casos, a dúvida quanto à classificação adequada, na falta de componentes tridimensionais da visão do processo. Mas, na realidade, mesmo quando se dispõe de um perfil mais completo de uma faixa móvel como um todo (Hatcher \& Williams, 1983), verifica-se que nem sempre é fácil, ou existe certo artificialismo em classificar adequadamente os diferentes domínios desenvolvidos e precisar seus limites. $O$ fato é que a deformação decresce de forma irregular das zonas mais internas (adjacências da sutura) até as zonas mais externas (interior do Cráton).

Como discutido no início do trabalho, a identificação das faixas móveis mesoproterozóicas foi dificil por várias razões, a que devem ser acrescentadas outras, relativas aos parágrafos iniciais deste item no tocante ao sistema Espinhaço-Chapada Diamantina Ocidental (na Bahia), onde ele é parte do núcleo cratônico sinbrasiliano do São Francisco. Há muitas feições de dobramento descontínuo envolvidas e faltam dados geofisicos que subsidiem, com suficiência, a proposta de uma interação de placas (ou de subplacas, como é o caso).

Este conceito de unidade orogênica foi introduzido informalmente em 1978 , durante a elaboração do Mapa Geológico do Estado da Bahia, por Cordani \& Brito Neves (1978), compondo a faixa mais jovem do embasamento do Cráton, consolidando várias opiniões prévias ("geossinclinal do Espinhaço", "oroaulacógeno", etc.) de mesmas tendências. No recente simpósio do Espinhaço, em Diamantina, 1995, as várias correntes de análise (Danderfer et al., 1993; Rocha \& Dominguez, 1993; Abreu, 1995, etc.) - em discussão de plenário - parecem convergir na admissão e linhas gerais da evolução de uma faixa móvel, com problemas maiores em Mi- nas Gerais, onde a sobreposição do Brasiliano foi penetrativa e importante. A discordância angular e erosiva que separa este sistema dos processos evolutivos subseqüentes do Ciclo Brasiliano, defendida desde a década de 60 , pelas exposições da Bahia (vide Brito Neves et al., 1979), parece agora extensivamente confirmada, em Minas Gerais inclusive (Braun et al., 1993; Souza Filho \& Alkmim, 1993; Abreu, 1995, etc.), face a novos dados de subsuperficie e outros de análise estrutural nos externides da Faixa Araçuaí.

Há naturalmente dissenções aspectos peculiares nos diversos exercícios de análise de conjunto, mas o principal enfoque da discussão está centrado na cronologia dos eventos. Para alguns autores a primeira fase de deformação (dobramento NS a NNW-SSE) já seria do Neoproterozóico (Rocha \& Dominguez, 1993; Danderfer et al., 1993, entre outros), com o que discordamos. O ponto de vista aqui reiterado é de uma deformação no Mesoproterozóico. Para as fases subsequientes, a idade neoproterozóica e o relacionamento estreito com 0 anel centrípeto de dobramentos brasilianos (são autênticos "thrust-and-fold belts") que envolve o Cráton do São Francisco são temas consensuais.

\section{Elementos da análise estrutural regio- nal}

A primeira fase deformacional do sistema de dobramentos é resultado de um campo de esforços compressionais E-W, no qual o acamadamento mostrouse mecanicamente ativo (deslizamento flexural, Danderfer Filho et al., 1993). Em vários setores da Chapada ocidental é possivel reconhecer foliação e/ou clivagem plano-axial franca nos vários braquidobramentos assimétricos desenvolvidos, associados com falhas de empurrão, do tipo reversas. Os indicadores cinemáticos são no sentido de transporte geral de WNE para ESE. De modo ge- 
ral, na Chapada é possível verificar uma deformação crescente de ENE (imediações do paralelo $10^{\circ} \mathrm{S}$ ) para SSW (imediações do paralelo $14^{\circ} \mathrm{S}$ ), passando-se gradativamente de estratos subhorizontais para dobramento expressivo, assimétrico, na parte mais ocidental da Chapada, e dai para estruturações mais complexas (incluindo retrabalhamento intenso no embasamento do bloco de Paramirim) para o domínio do Espinhaço (vide Fig. 6).

No Espinhaço Setentrional o dobramento é fechado, isoclinal, por vezes revirado e com flancos rompidos, com vergência forte para oeste, dando ao sistema em conjunto uma visão genérica de vergências centrifugas.

O propósito aqui é coligir uma série de evidências e argumentos (nem todos originais), de que esta deformação é do Mesoproterozóico, em torno de $1300 \mathrm{Ma}$, e mais enfaticamente reiterar uma tectônica claramente pré-Brasiliana. Destacamos

a) A discordância angular e erosiva, localmente mais conspícua, entre o dobramento do Supergrupo Espinhaço e o do Supergrupo São Francisco, é uma quebra estratigráfica que requereu espaço de tempo de alguns milhões de anos. Enquanto na Bahia esta é uma observação sem grandes problemas (domínio de cráton sinbrasiliano), em Minas Gerais, onde a Faixa Araçuaí é longitudinal ao Espinhaço (e a defomação brasiliana é muito forte), esta discordância só pode ser percebida nos externides, com dificuldades algumas vezes, ou então mediante circunstâncias especiais (dados de subsuperficie, análise das intrusivas máficas marcadoras no tempo, etc.). Ainda assim, estas dificuldades de percepção em Minas $\mathrm{Ge}$ rais são relativas, pois segundo Frederich Renger (informação verbal), o Supergrupo S.Francisco (representado pelo Grupo macaúbas) apresenta contatos claramente discordantes com pratica- mente todas as unidades do Supergrupo Espinhaço, como observado recentemente no desenvolvimento do mapeamento de semi-detalhe.

$\mathrm{Na}$ região central da Bahia, essa discordância angular e erosiva fora já discriminada, fotografada e publicada por Brito Neves, há trinta anos atrás, simplesmente revendo observações já expostas por Branner, no início do século.

b) A presença de importantes e espessos contingentes de clásticos continentais imaturos nas unidades basais ao Supergrupo São Francisco (Bebedouro, Macaúbas, Jequitaí) são atestados de interrupção expressiva, no desenvolvimento estratigráfico regional, em termos de tempo e ambiente (situadas entre unidades marinhas).

c) $\mathrm{O}$ fato concreto do Supergrupo São Francisco se alojar preferencialmente em baixos estruturais (sinclinais de Campinas, Iguitu, Amaniú, e sinformes de Irecê, Alto Paraguaçu) e erosionais (depressões importantes previamente esculpidas, com recuo de encostas) como aquelas da borda sul do bloco de Mimoso (o bloco mais setentrional da Chapada Diamantina, que chega próximo ao Rio S.Francisco) e da área de Xique-Xique (vide Fig. 6).

d) A marcante diferença de direções e estilos estruturais do Espinhaço ("primeira fase", NS-NNW) e do Supergrupo São Francisco, na Bahia. Este em grande parte com importante descolamento basal para o sul ("thin skin", direção geral E-W), flagrantemente discordante da deformação da Chapada Diamantina e Espinhaço, como tentativamente representados na Figura 6. Esta quase ortogonalidade de direções e de esforços seria incompativel com um único processo de interação de placas ou subplacas, pois exigiria uma mudança muito brusca no padrão de convecção do manto, ajustando-se mais aos processos de colagens (somatória de interações 


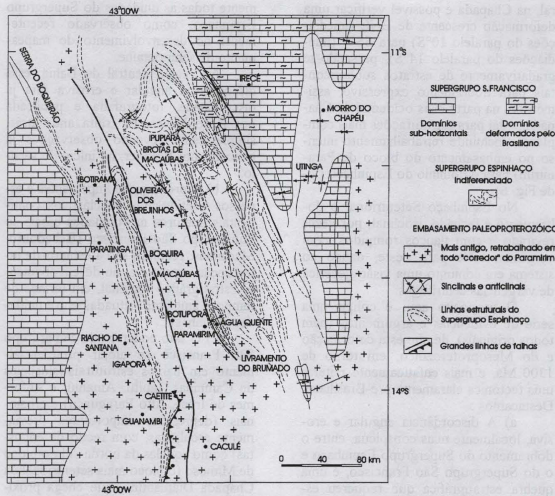

Figura 6 - As principais estruturas tectogênicas da Bahia Central, Sistema de Dobramentos Espinhaço (a oeste) - Chapada Ocidental (centro). É marcante a suavização da deformação para a Chapada Diamantina mais oriental, de sudoeste para nordeste. Observar a deformação brasiliana (direçб̃es E-W presente no interior das sinformes de Irecê (até o paralelo de $11^{\circ} 30^{\prime}$ ) e de Iguitú (oeste de Irecê), e completamente ausente tanto em todo o trecho a oeste de Ibotirama para o sul quanto na sinforme de Utinga.

Baseado em Inda e Barbosa (1978), Pedereira (1994), com adendos, modificaçöes e supressŏes dos autores.

em diferentes tempo ou somatória de orogêneses).

e) Além disto, a deformação NSNNW ocorre de forma bastante clara em alguns setores do Espinhaço - como por exemplo de Ibotirama para Paratinga -, e em outros setores da Chapada - como do sul de Canarana para Iraquara (sul do paralelo $11^{\circ} 30^{\prime}$ ) -, sem que a cobertura do Supergrupo São Francisco que lhe são sobrepostas e/ou adjacentes apre- sente quaisquer evidências dessa deformação (vide Fig. 6). Se a compressão da primeira fase fosse neoproterozóica (e adviesse do mesmo empuxo que dobrou a Faixa Brasília, como alegam os autores que se contrapõem à deformação mesoproterozóica) não havia como persistirem estes setores de franca subhorizontalidade do Bambuí embutidos na estruturação Espinhaço.

f) O magmatismo fissural básico 
que é característico da Chapada Diamantina e do Espinhaço, foi recentemente mapeado em semi-detalhe (Projeto Espinhaço, Geosol + Instituto de Geociências da UFMG, inédito), em Minas Gerais, mostra de forma inequivoca o tipo de relação crono-estratigráfico aqui defendido. Estas rochas, para as quais falta um estudo geocronológico adequado à sua importância (valores de idade aparente entre 1150 até $900 \mathrm{Ma}$ ), ocorrem recortando contextos tectogênicos prévios e já soerguidos e erodidos de alguma forma, do sistema Espinhaço-Chapada, e são unidades que precedem toda sedimentação neoproterozóica (Supergrupo São Francisco). São portentosos corpos magmáticos máficos (soleiras e diques), alguns de centenas de metros de espessura, de ocorrência franca e clara, discordantes das unidades previamente deformadas do Espinhaço e da Chapada, e que desaparecem no contato com o Supergrupo S.Francisco. Inchusive há de algumas evidências de fragmentos deste magmatismo nas porções basais das supracrustais neoproterozóicas (no Rio Pardo, e nas proximidades de Caatinga do Moura-BA, por exemplo).

Este magmatismo básico representa claramente os registros de uma ampla e importante fase distensional pós-orogênica, do final do Mesoproterozóico (provavelmente até o início do Neoproterozóico). Seu estudo geológico e geocronológico é prioritário, por sua expressão e significado, e porque trará os fatos e argumentos suficientes para encerrar uma polêmica que é (para nós) de há muito dispensável.

A idade desta primeira etapa deformacional é colocada no Mesoproterozóico com base na análise geológica a nivel regional e no modesto suporte geocronológico auferido até o momento, oriundo de diferentes objetivos e escalas de pesquisa. Destacamos os dados consignados nas rochas do embasamento retrabalhado do vale do Paramirim (Jardim de Sá et al., 1976; Turpin et al., 1988; Cordani et al., 1992) e no Domo de Bonfim, em Minas Gerais (Carneiro, 1992), nos valores de idades do magmatismo máfico (Brito Neves et al,, 1979; Machado et al., 1989), e ainda nas idades $\mathrm{Rb}-\mathrm{Sr}$ em pelitos anquimetamórficos (Brito Neves et al., 1989, valor de idade de $1290 \pm 52 \mathrm{Ma}$ ) e $\mathrm{Pb}-\mathrm{Pb}$ em carbonatos (Babinski et al., 1993, idade isocrônica de $1140 \pm 140 \mathrm{Ma}$ ) da Formação Caboclo, em Morro do Chapéu, resultados estes que estão destacados na Figura 7. Estes dados são relativamente coerentes entre si, e apontam para esta fase deformacional inter-regional uma idade na ordem de $1300 \mathrm{Ma}$, com estimativa de erro próximo a $5 \%$. Este valor deve ser compreendido como de reconhecimento, carente de posterior aperfeiçoamento, mas, insofismável na presente instância de análise.

Nestes termos, na abordagem como ciclo quelogênico, o Espinhaço teve seu início com a tafrogênese do Estateriano - autêntico "linked faul system" extensional e continental - e seu fechamento com esta fase orogênica do Ectasiano, em analogia e certa sincronia com o desenvolvimento Uruaçuano que lhe é paralelo no Brasil Central, e com ele completando um sistema ramificado ("branching system") de edificios orogênicos. Por ter sido a mais jovem faixa móvel da porção litosférica paleoproterozóica, onde se situa (ou seja, idade termal mais jovem), parece natural e esperável a constância como este sistema e seu embasamento (particularmente o "corredor do Paramirim") veio a ser reestruturado no ciclos sobrepostos.

A segunda etapa de deformação que atingiu o sistema é bastante conspicua e decantada em Minas Gerais (Faixa Araçuai subparalela ao Espinhaço), mas é suficientemente bem registrada por toda a Bahia. Esta deformação subsidiária da compressão das coberturas neo- 

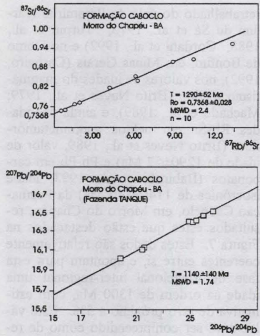

Figura 7 - As isócronas da Formação Caboclo, unidade do Grupo Chapada Diamantina, parte superior do Supergupo Espinhaço.

7a. Isócrona $\mathrm{Rb}-\mathrm{Sr}$ em folhelhos e siltitos (anquimetamórficos), nas imediaçőes a oeste de Morro do Chapéu-BA. Brito Neves et al. (1979), valor considerado minimo para a sedimentaçăo e próximo do evento de diastrofismo. 7b. Isócrona $\mathrm{Pb}-\mathrm{Pb}$ para os calcários estromatolíticos da Formação Caboclo, na Fazenda Tanque, $12 \mathrm{~km}$ oeste de Morro do Chapéu-BA, de Babinski et al. (1993). Estas rochas estão encaixadas nos folhelhos e siltitos acima da Formaçăo Caboclo, cuja determinação geocronológica Rb-Sr está na Figura 7a.

proterozóicas funcionou como um torniquete, circunscrevendo toda a então península do São Francisco. A conjunção da compressão vinculada ao transporte tectônico em busca do núcleo estável, do norte para o sul (originária nos Sistemas Sergipano, Riacho do PontalRio Preto) e do sul e para o norte (originária no ramo oriental do Araçuaí e no sistema Rio Pardo) estruturou vigorosamente essas faixas móveis perifranciscanas, e avançou cráton a dentro, configurando diversas manifestações tectô- nicas de antepais, como descolamentos "thin skin" centripetais, retrabalhamento do embasamento, retomada de antigas linhas de falha, enxames de diques, intrusivas alcalinas, privilegiando corredores de descontinuidades estruturais preexistentes e zonas de idade termal mais jovens. De sorte, que distinguir tratos realmente "full cratonic" no interior do contexto paleoproterozóico dito estável, ou seja, que tenham permanecido indenes à tectônica neoproterozóica é uma tarefa delicada, e sempre carente de revisão. Para o final das colisões brasilianas, há idades que variam de $550 \mathrm{Ma}$ a $510 \mathrm{Ma}$, mas é possível que outras fases deformacionais mais antigas tenham atuado e venham a ser identificadas.

\section{REPERCUSSÃO NO EMBASA- MENTO (REGISTRO NOS CRÁ- TONS DO CICLO BRASILIANO)}

A deformação das faixas móveis é propagada aos blocos adjacentes a diferentes distâncias, em consonância com a rigidez esperada para a litosfera. A deformação se propaga de várias formas e intensidades em niveis crustais rasos ("crack propagation") e mesmo profundos, conforme vários trabalhos preexistentes e outras análises mais recentes de revisão (vide Hancock, 1994). A deformação costuma se concentrar em prévias zonas de fraqueza, zonas de cisalhamentos ou lineamentos, sítios de atividade magmática mais jovens, mas também pode ocorrer através de mecanismos de dissolução por pressão. E estes processos, invariavelmente estão ligados com manifestações hidrotermais (com repercussão em muitos sistemas isotópicos).

O tema é vasto e tem sido tratado muitas vezes de forma vaga ou furtiva em geologia regional, e carece de aprofundamento, nos casos conhecidos do Brasil e alhures. 


\section{Amazônia}

No bloco paleoproterozóico da Amazônia, vários autores, em diferentes épocas abordaram o problema, no tocante a um evento marcante do Mesoproterozóico, a saber: Barron (1966, evento K'mudku, $1200 \mathrm{Ma}$, na Guiana), Priem et al. (1971, evento Nickeriano, no Suriname), Kloosterman (1973, evento Orinoquense, $1300-1200 \mathrm{Ma}$, na Venezuela), Lima et al. (1974, evento Jari-Falsino, 1200-1100 Ma, no Amapá e Pará), Amaral (1974, evento Rondoniense, 1050-900 Ma, posterior ao evento Madeirense, 1400-1250 Ma, no sudoeste da Amazônia), consoante a síntese de Amaral (1974, 1984), e praticamente em todas as folhas ao milionésimo do Projeto RadamBrasil. Invariavelmente, estes autores (que desginaram os eventos cratônicos) se referiram a cataclasitos, milonitos, basculamento de blocos, cisalhamento, dobramento idiomórfico, rejuvenescimento isotópico de rochas mais antigas, etc., em escala regional de observação. Quase sempre, os dados geocronológicos - $\mathrm{Rb}-\mathrm{Sr}$ e K-Ar em maioria - foram suporte importante de tais designações.

No caso da Amazônia, sem observações novas a aduzir, somos da opinião de que estes processos condizem com a propagação diversificada ("ativação reflexa") da deformação originada na colagem Grenville (orogenia anterior à Elzeviriana e eventos subseqủentes), conforme já haviam presumidos Kroonenberg (1982) e Priem et al. (1971). Isto se considerarmos a discussão acima e as configuraçōes de Litherland et al. (1985) e Hoffman (1991), mostrando o cinturão orogênico (Grenville-Sueco/ Norueguês-Garzon-etc.) circunscrevendo o bloco amazônico, e reunindo-o fortemente a outros congêneres, na aglutinação do supercontinente Rodinia.

Nas áreas adjacentes ao Grenville, no Canadá, há vários exemplos comparáveis de "resetting" de vários sistemas isotópicos, a nível de mineral e rocha total, descritos por vários autores, consoante a sintese de Easton (1986).

Adiantamos aqui que vários processos de deformação extensional se sobrepõem no tempo (idades mais jovens que $1150 \mathrm{Ma}$ ), com magmatismo associado (vide Quadro I), deixando bem marcado que os eventos de "reativação" (com cisalhamento e compressão envolvidos) pertenciam a outra fase e campos de esforços anteriores, de outra origem. Ou, em outras palavras, há várias fases a discriminar para estes processos cratônicos, entre reflexos (ativação tangencial na litosfera, antecedentes no tempo) e autônomos (atividade mantélica, instalada posteriormente).

\section{São Francisco}

No dominio do Cráton do São Francisco, processos semelhantes foram identificados primeiramente por Herz (1970), discriminando dois eventos térmicos, um de 1350 e outro de $1000 \mathrm{Ma}$ (dados $\mathrm{Rb}-\mathrm{Sr}$ e $\mathrm{K}-\mathrm{Ar}$ ), afetando embasamento e supracrustais mais antigos do Quadrilátero Ferrífero. Estes dados e estes eventos são por nós interpretados como reflexos distais do fecho dos orógenos das faixas do Espinhaço (a leste) e do Uruaçuano (a oeste, e possivelmente a sul), na metade do período Ectasiano, e subsequientes.

No Complexo Metamórfico de Bonfim, a oeste do Quadrilátero, foram identificadas recentemente várias unidades ortoderivadas de alto grau (contexto polidiapírico) arqueanas, e penetrando substrato arqueano (gnaisses trondhjemiticos "Alberto Flores") de natureza granitica ("Gnaisses Souza Nochese") e tonalítica ("Samambaia"), e ainda corpos filonares locais ("Brumadinho"), os quais são caracterizados por diagramas isocrônicos do final do $\mathrm{Me}$ soproterozóico, consoante Carneiro (1992). No caso das intrusivas filonares, há indicações pelo método $\mathrm{U}-\mathrm{Pb}$ 
Quadro 1 - Processos e eventos associados às tafrogêneses e os dados isotópicos disponiveis

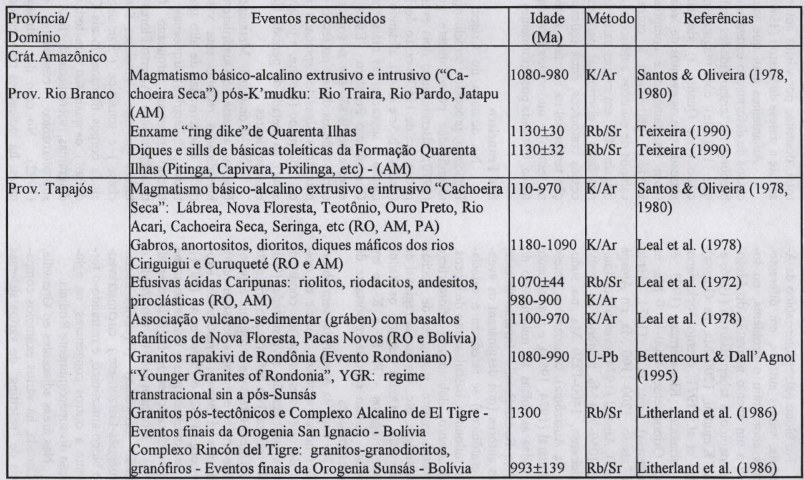


Quadro 1 (continuação).

\begin{tabular}{|c|c|c|c|c|}
\hline $\begin{array}{l}\text { Província/ } \\
\text { Dominio }\end{array}$ & Eventos reconhecidos & $\begin{array}{l}\text { Idade } \\
\text { (Ma) }\end{array}$ & Método & Referências \\
\hline $\begin{array}{l}\text { Crát.S.Francisco } \\
\text { Borda Oriental } \\
\end{array}$ & $\begin{array}{l}\text { Magmatismo básico fussiral toleítico de Salvador, Illheus, } \\
\text { Olivença, Itajai de Colorio, Camacã. Basaltos toleíticos, } \\
\text { andesi-basaltos }\end{array}$ & $1070-1000$ & $\mathrm{Ar} / \mathrm{Ar}$ & $\begin{array}{l}\text { D'Agrella \& Paca (1993), } \\
\text { Brito et al. (1990), } \\
\text { Oliveira et al. (1984) }\end{array}$ \\
\hline mato ourticat & $\begin{array}{l}\text { Enxames de diques do Espinhaço em Minas Gerais, diversos } \\
\text { tipos ("Básica de Pedro Lessa") } \\
\text { Glaciação Bebedouro-Jequitai e tafrogênese associada } \\
\text { Diques e enxames básicos do Espinhaço na Bahia, diversos } \\
\text { tipos. Gabro fresco de Cacimba de Dentro** }\end{array}$ & $\begin{array}{l}1070-1000 \\
(906 \pm 2 *) \\
+1000 \mathrm{Ma} \\
1200-1100 \\
(1111 \pm 96 * *)\end{array}$ & $\begin{array}{l}\mathrm{K} / \mathrm{Ar} \\
\mathrm{U} / \mathrm{Pb} \\
\mathrm{K} / \mathrm{Ar} \\
\mathrm{K} / \mathrm{Ar}\end{array}$ & $\begin{array}{l}\text { Brito Neves et al. (1989), } \\
\text { Machado et al. (1989), } \\
\text { Karfunkel \& Hope (1988), } \\
\text { Brito Neves et al. (1979) } \\
\text { Jardim de Sá et al. (1978) }\end{array}$ \\
\hline Parte Sul & $\begin{array}{l}\text { Corpo diabásico e enxames de diques (direção NW) máficos } \\
\text { Conceição de Itaguá, basaltos, lati-andesitos. Enxame de } \\
\text { diques do sul de Minas Gerais e do Quadrilátero Ferrifero. } \\
\text { Extensão pós-Uruaçuana, "rift-basins" e "passive margin } \\
\text { basins", pré-deformação brasiliana }\end{array}$ & $\begin{array}{l}1100-900 \\
1006 \pm 43 \\
s / \text { dados }\end{array}$ & $\begin{array}{l}\mathrm{Ar} / \mathrm{Ar} \\
\mathrm{K} / \mathrm{Ar}\end{array}$ & $\begin{array}{l}\text { Marshak \& Alkmim } \\
\text { (1989) }\end{array}$ \\
\hline $\begin{array}{l}\text { Crát.Rio de La } \\
\text { Plata }\end{array}$ & $\begin{array}{l}\text { Basaltos pré-orogênicos não metamórficos, dobrados } \\
\text { concordantemente com encaixantes filíticas no Uruguai } \\
\text { Centro Oriental }\end{array}$ & $900 \pm 50$ & $\mathrm{~K} / \mathrm{Ar}$ & $\begin{array}{l}\text { Bossi \& Campal (1992) } \\
\text { Ramos et al. (1994) }\end{array}$ \\
\hline $\begin{array}{l}\text { Crát.Pampia e } \\
\text { Arequipa-Amofalla }\end{array}$ & Instalação e evolução da Bacia Puncoviscana & $>700$ & $\mathrm{~K} / \mathrm{Ar}$ & Ramos et al. (1994) \\
\hline
\end{tabular}


Quadro 1 (conclusão).

\begin{tabular}{|c|c|c|c|c|}
\hline $\begin{array}{l}\text { Província/ } \\
\text { Domínio }\end{array}$ & Eventos reconhecidos & $\begin{array}{l}\text { Idade } \\
(\mathrm{Ma})\end{array}$ & Método & Referências \\
\hline $\begin{array}{l}\text { Prov. Borborema } \\
\text { (zona transversal e } \\
\text { ramo sul) }\end{array}$ & $\begin{array}{l}\text { Vulcanismo bi-modal, riolítico (predominante) e basáltico } \\
\text { associados a rifteamento nas faixas Riacho Pontal, Sergipana, } \\
\text { Pajeu-Paraíba e Piancó-Alto Brígida. Localmente (Piancó, } \\
\text { Jaguaribeano, vulcanismo máfico de afinidade MORB) }\end{array}$ & $1100-1000$ & $\mathrm{U} / \mathrm{Pb}$ & Brito Neves et al. (1993) \\
\hline $\begin{array}{l}\text { Provincia Tocantins } \\
\text { Ramo ocidental }\end{array}$ & $\begin{array}{l}\text { Rifteamento e processos precursores (implícitos) ao } \\
\text { desenvolvimento do ambiente de arcos de ilhas do sudoeste } \\
\text { goiano }\end{array}$ & $>900 \mathrm{Ma}$ & $\mathrm{U} / \mathrm{Pb}$ & Pimentel et al. (1991) \\
\hline Ramo Oriental & $\begin{array}{l}\text { Evento tectono-sedimentar Paranoá, extensão crustal lístrica } \\
\text { pós-distrofismo Araí. } \\
\text { Ruptura litosférica e formação de grabens. Vulcano- } \\
\text { plutonismo Maratá, pós-rifteamento (colisional) }\end{array}$ & $\begin{array}{l}<1300 \\
>784 \pm 10\end{array}$ & $\mathrm{U} / \mathrm{Pb}$ & $\begin{array}{l}\text { Farias (1993) } \\
\text { Pimentel et al. (1992) }\end{array}$ \\
\hline $\begin{array}{l}\text { Prov, Mantiqueira } \\
\text { Seg. Setentrional }\end{array}$ & $\begin{array}{l}\text { Glaciação Bebedouro-Jequitaí e tafrogênese associada. } \\
\text { Magmatismo basáltico de filiação toleitica de Capelinha } \\
\text { ("ofiolitos") }\end{array}$ & $\begin{array}{l} \pm 1000 \\
793 \pm 9 \\
1040-960\end{array}$ & $\begin{array}{l}\mathrm{Sm} / \mathrm{Nd} \\
\mathrm{Tdn}\end{array}$ & $\begin{array}{l}\text { Karfunkel \& Hope (1988), } \\
\text { Pedrosa Soares et al. } \\
\text { (1992) }\end{array}$ \\
\hline Seg. Central & $\begin{array}{l}\text { Doleritos toleíticos e vulcânicas ultrapotássicas ("lamproitos") } \\
\text { da parte sul da Faixa Itaiacoca. Rifteamento Abapã }\end{array}$ & $1250-1080$ & $\mathrm{Rb} / \mathrm{Sr}$ & Reis Neto (1994) \\
\hline Seg. Meridional & $\begin{array}{l}\text { Basaltos pré-orogênicos não metamórficos, Uruguai Oriental. } \\
\text { Estágio de rifteamento, precedendo o evento orgenético São } \\
\text { Gabriel }\end{array}$ & $\begin{array}{l}900 \pm 90 \\
1000-790\end{array}$ & $\mathrm{~K} / \mathrm{Ar}$ & $\begin{array}{l}\text { Bossi \& Campal (1992), } \\
\text { Chemale et al. (1995) }\end{array}$ \\
\hline
\end{tabular}


em zircão (intercepto inferior) de perda $\mathrm{de} \mathrm{Pb}$ no mesmo período. Interessante registrar que o substrato dominante ("Alberto Flores") não apresentou indícios quaisquer do "resetting", que se mostra exclusivo das intrusões arqueanas (idades $\mathrm{U}-\mathrm{Pb}$ irrepreensiveis).

Todas as linhas isocrônicas traçadas por Carneiro (1992), constantes como Figuras 8a, 8b, 8c, neste trabalho, mostram valores elevados da razão $\mathrm{Rb}-$ $\mathrm{Sr}$ e, mais ainda, das razões $\mathrm{Sr}^{87} / \mathrm{Sr}^{86}$, podendo ser enquadradas no modelo 1 de Maheteney (1990), já comentado. Os dados petrográficos, isotópicos e tectônicos são indicativos de vigorosa difusão do $\mathrm{Sr}^{87}$ radiogênico, o que está sendo atribuido à retomada das zonas de cisalhamento antigas (muitas delas arqueanas) pela deformação mesoproterozóica, consoante evidências de mega a microescala. A re-homogenização dos sistemas $\mathrm{Rb}-\mathrm{Sr}$ se verifica diante da transformação de minerais de potássio, por ação de fluidos silicáticos, na fácies xistos verdes (Carneiro, 1992).

No magmatismo básico fissural (basaltos e lati-andesitos, baixo grau de metamorfismo) que recorta sistematicamente esta área, determinações K-Ar em hornblendas (magmatismo "Conceição de Itaguá", diques de direção NW e stocks) indicam valores de $1006 \pm 43 \mathrm{Ma}$, como registrado no Quadro I. Estas idades aparentes podem estar refletindo o mesmo evento mesoproterozóico (interpretação original de Carneiro, 1992), mas, é bem mais provável que já estejam relacionadas com o tectonismo extensional posterior, como já verificado na Amazônia.

Nas imediações do Espinhaço e da Chapada Diamantina, na Bahia, há vários fenômenos semelhantes, sem o mesmo acervo qualitativo de dados geocronológicos, evidenciando retrabalhamento a diversos níveis de rochas do embasamento, seja este "granite-greenstone", gnáissico-migmatítico ou mesmo
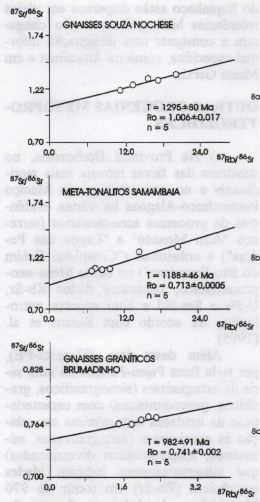

Figura 8 - As isócronas do Complexo Metamórfico de Bonfim, a oeste do Quadrilátero Ferrifero (rochas com idades arqueanas segundo dados U-Pb em zircão de Carneiro (1993), indicando a forte re-homogeneização (retrabalhamento) mesoproterozóico.

8a. Ortognaisses de composição granitica, foliados ou bandados.

8b. Ortognaisses leucocráticos, médios a grosseiros, composição tonalítica (intrusivos nos anteriores?). As texturas igneas estão preservadas.

8c. Ortognaisses leucocráticos, formas de diques ou de pequenas bossas (intrusivo no tonalito Samambaia).

faixas móveis paleoproterozóicas (caso da Serra de Jacobina). Estes dados, que mostram a irradiação lateral de esforços 
do Espinhaço estão dispersos em várias referências bibliográficas e não chegaram a consignar uma designação informal especifica, como na Amazônia e em Minas Gerais.

\section{OUTRAS OROGENIAS MESOPRO- TEROZÓICAS}

a) $\mathrm{Na}$ Província Borborema, no substrato das faixas móveis mais meridionais e no embasamento do Maciço Pernambuco-Alagoas há várias evidências de processos acrescionários (terrenos "Alto Moxotó" e "Lagoa das Pedras") e colisionais ("Complexo Belém do São Francisco") no limite Meso-neoproterozóico, consoante dados $\mathrm{Rb}-\mathrm{Sr}$, $\mathrm{U}-\mathrm{Pb}$ e $\mathrm{Sm}-\mathrm{Nd}$ e bom suporte petrológico, de acordo com Santos et al. (1995).

Além desta área (Floresta-PE), por toda faixa Pajeú-Paraiba há uma série de ortognaisses (sienograníticos, graníticos, granodioríticos) com características de unidades sintectônicas em relação às encaixantes (metagrauvacas, micaxistos, metavulcânicas diversificadas) que sistematicamente indicam idades isocrônicas (Rb-Sr) em torno de 970 Ma. Valores de idades semelhantes são encontradas na porção mais ocidental do embasamento do Maciço PernambucoAlagoas, em ortognaisses do Sistema Riacho do Pontal e em supracrustais (metavulcânicas félsicas) do Sistema Piancó-Alto Brígida (geradas na tafrogênese de 1200-1100 Ma).

A história e a extensão desta orogenia, chamada provisoriamente de "Cariris Velhos" (Campos Neto et al., 1994; Brito Neves et al., 1995) é problema em aberto, de conhecimento recente e de muito futuro na pesquisa geológica daquela província. Há indicações de que em parte ela é a consumação de um ciclo iniciado com a tafrogênese de $1150-1100 \mathrm{Ma}$, e que em parte (em outras faixas), ela é quase contemporânea.
A relação deste processo de interação com o de Sunsás-Aguapeí (de mesma idade), e com outros síncronos a nivel mundial (Ottawan, do Grenville) é tema bastante atraente e inadiável de pesquisa.

b) No Uruguai, a sudeste dos terrenos Nico Perez e Piedras Altas, Campal et al. (1995) e Gaucher \& Sprechmann (1995) apresentam uma série de evidências preliminares da presença do Ciclo Uruaçuano naquele país, subseqüente aos processos tafrogenéticos do Estateriano, e sotoposto por discordância a metassedimentos vendianos.

A formação Cerro Villalba é descrita como composta por metacarbonatos e argilas, com vários tipos de estromatólitos do mesoproterozóico. Ela apresenta uma primeira fase de deformação (orientação N-S), que lhe é exclusiva, e uma fase subseqüente (E-W) conjunta com os metassedimentos vendianos. Além da discordância estrutural, esta unidade é recortada por diques graníticos, indicando pois a relevância do hiato temporal entre ela e a unidade neoproterozóica sobrejacente (Arroyo del Soldado).

Algumas determinações K-Ar em minerais dos planos de deformação e outras determinações $\mathrm{Rb}-\mathrm{Sr}$ e $\mathrm{Ar}$-Ar em diques máficos (de idade original no Estateriano) apontam idades entre 1400 e $1200 \mathrm{Ma}$, interpretadas por aqueles autores como relativas a um ciclo de sedimentação $(>1400)$ e deformação, semelhante ao Uruaçuano do Brasil.

As informações são a nível preliminar, de resumos expandidos, mas muito interessantes, principalmente pela nítida evolução pós-tafrogênese estateriana dos sedimentos (sobrepostos a diques máficos e batólitos graníticos de $1700-1880 \mathrm{Ma}$, isto combinado com outos dados de cunho paleontológico), e as evidências de deformação mesoproterozóica. 


\section{PROCESSOS DE TAFROGÊNESE}

Os eventos de tectônica extensional, com magmatismo e sedimentação associados, posteriores às orogenias da parte superior do mesoproterozóico são conhecidos em todas as províncias estruturais brasileiras, com a diversidade esperada, embora com nível sofrivel no conhecimento geológico geral (petrologia, geoquímica) e geocronológico. Este tipo de análise conjunta é pioneiro e se defronta com estes problemas, e mais ainda, com a catalogação de todas as ocorrências prováveis de unidades litoestruturais desenvolvidas na sequiência imediata destes eventos colisionais no continente.

A forma mais adequada que encontramos - e muito simplista - de análise é o confronto de uma sintese da vasta bibliografia nestas unidades, como tentativamente executado no Quadro I, anexo.

É possivel, de forma preliminar, distinguir dois conjuntos de eventos tafrogenéticos do Estateriano ao Toniano, cujos limites cronológicos não podem ainda ser fixados com rigor, pela escassez dos dados, e, talvez, porque realmente tenha havido certa concorrência em tempo destes eventos, de uma província a outra.

a) $\mathrm{O}$ primeiro conjunto se refere aos processos rupturais generalizados, com magmatismo básico toleítico (sobrepujante) e básico-alcalino, com ocorrência subordinada de plutonismo granitico (Rondônia) e alcalino (Bolívia), que privilegiou o bloco amazônico (e especialmente sua porção mais ocidental).

Do mesmo conjunto e idades destacamos os processos de rifteamento, sedimentação clástica e vulcanismo bimodal que precedeu o desenvolvimento das faixas móveis da Borborema (riolitos $\gg$ basaltos) e das faixas móveis do segmento central da Faixa Ribeira (Itaiacoca), na borda oriental do Cráton
Paraná. O rifte do Paranoá (ainda que sem magmatismo reconhecido ainda) faz parte do mesmo contexto.

Ainda que os dados de geocronologia sejam muito precários, o vulcanismo básico do Espinhaço baiano e mineiro, pelo menos em parte, pode ser referido a este intervalo de tempo (final do Mesoproterozóico e inicio do Neoproterozóico) e a categoria de eventos pós-orogênicos.

Estes eventos são imediatamente posteriores. Em tempo, aos processos da colagem orogênica San Ignácio-Uruaçuano-Espinhaço, ficando no tempo do final do Ectasiano para o Esteniano (valores de idade entre 1300 e $1100 \mathrm{Ma}$ ). Em alguns casos, estes valores de idade (e dados de campo) mostram que o processos extensionais sucederam os eventos de "reativação" dos crátons já discutidos. Parte destas rochas vulcânicas, plutônicas e sedimentares então formadas foram envolvidas - em circunstâncias especiais - em processos orogenéticos, como na Bolivia e Amazonas Ocidental (Sunsás-Aguapeí), na Borborema ("Orogênese Cariris Velhos") e na Ribeira Central ("Orogênese Cunhaporanga"), na parte inicial do Neoproterozóico.

b) O segundo conjunto de processos extensionais é mais variável em idade (de 1100 a $950 \mathrm{Ma}$, com alguns valores chegando a $700 \mathrm{Ma}$ ), com várias evidências de rifteamento acompanhado de rochas basálticas toleiticas como as mais típicas das litologias formadas. $\mathrm{O}$ limite superior de idade deste conjunto é dificil de separar do limite inferior do outro conjunto acima proposto, e é possível que esta separação seja algo artificial. Ou seja, na prática, há certa sobreposição do segundo conjunto com relação ao primeiro (como na África, vide Porada, 1989).

Destacamos o magmatismo básico toleítico da borda oriental, sul oriental e sul do Cráton do São Francisco, da 
borda leste do Cráton do Rio de La Plata e do bloco São Gabriel. Da mesma forma como temos algumas evidências de rifteamento nas bordas ocidental (Bacia Puncoviscana) e oriental (Faixa Cordobana) do Cráton Pampia, no ramo ocidental e oriental (Rifte Paranoá) da Província Tocantins, etc. Evidentemente, estes processos rupturais e de magmatismo guardam alguma sincronia em termos de tempo, de uma província a outra, mas não necessariamente, e o desfecho de todos eles é o desenvolvimento dos ambientes tectônicos e bacinais da parte inicial do Ciclo Brasiliano.

Em África, estes processos são de há muito conhecidos, principalmente os do segundo conjunto de dados, consoante excelente trabalho de Porada (1989), que identificou o intervalo de 1100-1000 Ma como a etapa de predomínio destes processos (e colocou uma interrogação no prolongamento deles para o nosso lado ocidental de Gondwana). Mas, o mais interessante foi que ele conseguiu traçar uma curva mostrando a variação nas idades, de uma faixa móvel (panafricana) para outra, desde os valores de $1110 \mathrm{Ma}$ até valores de $630 \mathrm{Ma}$. No Brasil, não temos dados suficientes para tal exercício.

\section{ENSAIOS DE CORRELACÃO}

A comparação da evolução observada no Brasil (Gondwana Ocidental) com a dos blocos proterozóicos do hemisfério setentrional (Laurásia) é um exercício interessante, malgrado a considerável diferença nas massas críticas de dados nos dois hemisférios, e traz à tona uma série de observações comparativas valiosas.

A comparação fica dificil quando feita com os diferentes setores da colagem Grenville, tais como apresentadas na sintese de Easton (1986) para o bloco norte-americano. $\mathrm{O}$ exercício flui melhor quando se toma a sintese do con- junto (Laurentia + Groenlândia + Báltica + Laurásia), em escalas menores, como aquela processada por Gower (1992).

Verifica-se uma série de identificações a serem destacadas:

a) Natureza e constituição do embasamento dos blocos paleoproterozóicos, com alguns núcleos arqueanos amalgamados por faixas móveis orosirianas, predominantes em área.

b) Rochas ígneas pós-orogênicas e sequências sedimentares de riftes do Estateriano.

c) Processos acrescionários precursores, com suas associações ígneas típicas, e com aglutinação de blocos, na orogênese Gothian-Kongsbergian"Transcontinental" (= Rio Negro-Juruena), entre 1,75-1,5 Ga. Processos cratogênicos sedimentares e magmáticos subseqüentes, em várias fases.

d) Acresção significativa na orogênese de 1,27-1,20 Ga (Elzeviriana), presente em vários setores da colagem grenvilliana, e com notáveis eventos subsidiários de "resetting" de rochas do embasamento. É possivel que em nosso continente, pelos dados acima apresentados, que estas orogênese/interações mesoproterozóicas (San Ignácio + Uruaçuano + Espinhaço) sejam um pouco mais antigas, na ordem de algumas dezenas de milhões de anos (valores até pouco acima de $1,3 \mathrm{Ga}$ são encontrados).

e) Tectônica extensional com vulcanismo básico e sedimentos clásticos associados (suítes AMCG muito típicas nos blocos do norte), entre 1,2 e 1,09 $\mathrm{Ga}$. Associações idênticas nos blocos do sul são conhecidas na mesma faixa de idade, mas sem um controle de idades ideal, não se podendo discriminar esta fase extensional (imediatamente pósorogênese) de outras mais jovens sobrepostas, que adentram o Neoproterozóico.

f) Magmatismo e orogênese (entre 
1,09 e $0,95 \mathrm{Ga}$, "Ottawana", Sueco-Norueguesa) muito bem marcada cronologicamente nos blocos laurasianos, correspondendo à máxima de aglutinação de massas crustais (e evocada sempre como de consumação de Rodínia). Nos blocos do sul, ocorrem registros similares na zona andina, na zona lindeira Brasil-Bolivia - Sunsás-Aguapeí -, há algumas indicações na Província Tocantins e na Província Borborema "Orogênese Cariris Velhos" -, e, subsidiariamente, alguns valores de retrabalhamento do embasamento. Mas, em todos estes casos, tanto o conhecimento dos processos crustais como assinatura isotópica requerem aprimoramentos.

g) Tafrogênese precursora dos processos evolutivos do Neoproterozóico (do Ciclo Brasiliano), diacrônica por todo o continente (de 1,1 a 0,7 Ga) de Gondwana Ocidental, sem equivalente nos blocos setentrionais, ou só localmente desenvolvida (a abertura do oceano Iapetus é colocada em torno de $0,6 \mathrm{Ga}$ ).

Estes dados do hemisfério sul se coadunam com a hipótese do Supercontinente Rodínia e abrem novas perspectivas de exame do problema. Pelos dados discutidos para o Brasil, há evidências de que o grande evento de fusão continental foi algo mais antigo, na parte mais inferior do Ectasiano ( $\cong 1,3 \mathrm{Ga}$ ), tendo os processos do Toniano (início do Neoproterozóico, $\cong 0,96 \mathrm{Ga}$ ) por complemento, e isto é uma diferença significativa para blocos setentrionais.

Os papéis das orogenias SunsásAguapeí e Cariris Velhos no contexto da aglutinação final de Rodínia ainda não são claros, por várias razões, de ordem palinspática, devido à sobreposição dos ciclos neoproterozóicos e fanerozóicos, deficiência de dados paleomagnéticos, etc. Mas, estas constatações abrem muitos campos novos de estudos, alguns insuspeitáveis há poucos anos atrás, e mesmo alguns imprescindiveis e urgen- tes, obrigando colocarem a geologia do nosso continente no alvo das metas de pesquisas a advir e de muitas reflexões sempre que Rodinia for o tema.

\section{REFERÊNCIAS BIBLIOGRÁFICAS}

ABREU, P.A.A. (1995) O Supergrupo

Espinhaço na Serra do Espinhaço Meridional (Minas Gerais): o rifte, a bacia e o orógeno. Geonomos, v.3, n. 1, p.1-18.

ALMEIDA, F.F.M. (1978) A evolução dos Crátons Amazônico e do São Francisco comparada com a de seus homólogos do Hemisfério Norte. In: CONGRESSO BRASILEIRO DE GEOLOGIA, 30, Recife, 1978 Anais. Recife, SBG, v.6, p.23932399.

ALMEIDA, F.F.M. (1968) Evolução tectônica do Centro-oeste brasileiro no Proterozóico Superior. Anais da Academia Brasileira de Ciências, suplemento, v.40, p.285-296.

ALMEIDA, F.F.M. (1969) Divisão crono-estratigráfica do Pré-Cambriano da Plataforma Brasileira. In: CONGRESSO BRASILEIRO DE GEOLOGIA, 23., Salvador, 1969. Resumo das Comunicaçôes. Salvador, SBG, v.1, p. 57 .

ALMEIDA, F.F.M. (1971) Geochronological Division of the Precambrian of South America. Revista Brasileira de Geociências, v.1, n.1, p. 13-21.

ALMEIDA, F.F.M. (1981) O Cráton do Paramirim e suas relações com o do São Francisco. In: SIMPÓSIO SOBRE O CRÁTON DO SÃO FRANCISCO E SUAS FAIXAS MARGINAIS, 1., Salvador, 1981. Anais. Salvador, SME/CPM/SBG/Núcleo da Bahia, v.1, p. 1-10.

ALMEIDA, F.F.M; AMARAL, G.; CORDANI, U.G.; KAWASHITA, K. (1973) The Precambrian evolution of the South American cratonic margin 
south of the Amazonia River. In: NAIRN, A.E.M:; STEHLI, F.G. (eds.) The ocean basins and margins, v.1, New York, Plenum Publish. Co., p.411-446.

AMARAL, G. (1974) Geologia PréCambriana da região Amazônica. São Paulo, 212p. (Tese - Doutorado) - Instituto de Geociências, Universidade de São Paulo.

AMARAL, G. (1984) Províncias Tapajós e Rio Branco. In: ALMEIDA, F.F.M; HASUI, Y. (coords.) O PréCambriano do Brasil. São Paulo, Edgard Blücher, p.6-35.

BABINSKI, M; VAN SCHMUS, W.R; CHEMALE Jr., F; BRITO NEVES, B.B.; ROCHA, A.J.D. (1993) Idade isocrônica $\mathrm{Pb} / \mathrm{Pb}$ em rochas carbonáticas da Formação $\mathrm{Ca}$ boclo, em Morro do Chapéu-BA. In: SIMPÓSIO SOBRE O CRÁTON DO SÄO FRANCISCO, 2, Salvador, 1993. Anais. Salvador, SBG/ SGM, v.1, p.160-163.

BETTENCOURT, J.S; DALL'AGNOL, R. (1995) The rapakvi granites of the Rondônia Tin Province and associated mineralizations. In: SYMPOSIUM ON RAPAKIVI GRANITES AND RELATED ROCKS. Belém, 1995. Excursion Guide. Belém, IGCP Project 315/ Centro de Geociências da UFPA, $48 \mathrm{p}$.

BOSSI, J.; CAMPAL, N. (1992) Magmatismo y tectónica transcurrente durante el Paleozoico Inferior in Uruguay. In: GUTIERREZ-MARCO, J.C.; SAAVEDRA, J.; RABANO, I. (eds.) Paleozoic Inferior de Ibero-America. Madrid, Universidad de Extremadura, p.342-356.

BOSSI, J.; CAMPALL, N.; CIVETTA, L.; DEMARCHI, G.; GIRARDI, V.A.V.; MAZZUCHELLI, M; NEGRINI, L; RIVALENTI, G; CESAR, A.R.F.; SINIGOI, S.; TEIXEIRA, W; PICCIRILLO, E.M;
MOLESINI, M. (1993) Early Proterozoic dike swarms from western Uruguay: geochemistry, $\mathrm{Sr}-\mathrm{Nd}$ isotopes and petrogenesis. Chemical Geology, v. 106, n.3-4, p. 263-277.

BOSSI, J;; CAMPAL, N.; GARAT, I.; PINERO, D.; RIFAS, C.G. (1989) First integrated photogeological map of the precambrian dike swarm of Uruguay: some geological inferences. Boletim IG-USP, Série Científica, v. 20, p.57-60.

BRAUN, O.P.G; MARTINS, M.; OLIVEIRA, W.J. (1993) Continuidade das sequêencias rifeanas sob a Bacia de São Francisco constatada por levantamentos geofísicos. In: SIMPÓSIO SOBRE O CRÁTON DO SÃO FRANCISCO, 2., Salvador, 1993. Anais. Salvador, SBG/ SGM, v. 1, p.164-166.

BRITO NEVES, B.B. (1995) A Tafogênese Estateriana no continente SulAmericano. In: SIMPÓSIO DE GEOLOGIA DE MINAS GERAIS, 8., Diamantina, 1995. Anais. Diamantina, SBG-Núcleo Minas Gerais, Boletim, p.48-49.

BRITO NEVES, B.B.; KAWASHITA, K; CORDANI, U.; DELHAL, J. (1979) A evolução geocronológica da Cordilheira do Espinhaço: dados novos e integração. Revista Brasileira de Geociências, v.9, n.1, p.7185.

BRITO NEVES, B.B; SÁ, J.M; NILSON, A.A; BOTELHO, N.F. (1995) A Tafrogênese Estateriana nos blocos paleoproterozóicos da América do Sul e processos subsequientes. Geonomos, v.3, n.2, p.1-21.

BRITO NEVES, B.B; VAN SCHMUS, W.R.; HACKSPACHER, P.C.; SANTOS, E.J. (1995) Geocronologia da Borborema, 1995: os fatos e as questões abertas. In: SIMPÓSIO DE GEOLOGIA DO NORDESTE, 16. Recife, 1995. Resumos Expandidos. Recife, SBG/Núcleo Nordeste, 
p. $410-413$.

BRITO NEVES, B.B.; VAN SCHMUS, W.R.; BABINSKI, M.; SABIN, T. (1993) O evento de magmatismo de $1,0 \mathrm{Ga}$ nas faixas móveis ao norte do Cráton do São Francisco, 2., Salvador, 1993. Anais. Salvador, SBG/SGM, v.1, p.243-245.

CAMPAL, N.; GAUCHER, C.; SCHIPILOV, A.; BOSSI, J. (1995) El Uruaçuano en El Uruguay: evidências geológicas, paleontológicas y radiométricas. In: SIMPÓSIO SUL BRASILEIRO DE GEOLOGIA, 6./ ENCONTRO DE GEOLOGIA DO CONE SUL, 1., Porto Alegre, 1995. Boletim de Resumos Expandidos. Porto Alegre, SBG/Núcleo RS, p.97100.

CAMPOS NETO, M.C.; BITTAR, S.M.B.; BRITO NEVES, B.B. (1994) Domínio tectônico do Rio Pajeú-Província Borborema: orogêneses superpostas no Ciclo Brasiliano/Pan-Africano. In: CONGRESSO BRASILEIRO DE GEOLOGIA, 38., Balnéario Camboriú, 1994. Boletim de Resumos expandidos. Balneário Camboriú, SBG, v.1, p.221-222.

CARNEIRO, M.A. (1992) O complexo Metamórfico Bonfim Setentrional (Quadrilátero Ferrifero, Minas Gerais): litoestratigrafia e evolução geológica de um segmento de crosta continental arqueana. São Paulo, 233p. (Tese - Doutorado) Instituto de Geociências, Universidade de São Paulo.

CHEMALLE Jr., F.; GRESSE, P.G.; SILVA, L.C.; HARTMANN, L.A.; WALRAVEN, F. (1995) Tectonic evolution of the Brasiliano Pan African Cycle in Southern Brazil and South Africa. In: SIMPÓSIO NACIONAL DE ESTUDOS TECTÔNICOS, 5., Gramado, 1995. Boletim de Resumos Expandidos, Gramado, SBG - Núcleo RS/CPSQUFRGS, p. 14.
COBBING, E.; OZARD, J.M.; SNELLING, N.J. (1977) Reconnaissance geochronology of the crystalline basement rocks of the Coastal Cordillera of Southern Peru. Geological Society of American Bulletin, v.88, n.2, p. 241-246.

CONDIE, K.C. (1989) Plate Tectonics and crustal evolution. 3. ed., Oxford, Pergamon Press, 476p.

CORDANI, U.G.; BRITO NEVES, B.B. (1978) Geocronologia do PréCambriano. In: INDA, H.A.V.; BARBOSA, J.F. (eds.). Texto Explicativo para o Mapa Geológico do Estado da Bahia Escala 1:1.000.000. Secretaria de Minas e Energia, Coordenação da Produção Mineral, Salvador-Bahia, p.32-49.

CORDANI, U.G.; YIER, S.S.; TAYLOR, P.N.; KAWASHITA, K; SATO, K.; McREATH, I. (1992) Pb$\mathrm{Pb}, \mathrm{Rb}-\mathrm{Sr}$ and $\mathrm{K}-\mathrm{Ar}$ systematics of the Lagoa Real uranium province (south-central Bahia, Brazil) and the Espinhaço Cycle. Journal of South American Earth Science, v.5, n.1, p.33-46.

CORREIA, C.T. (1994) Petrologia do Complexo máfico-ultramáfico de Cana Brava, Goiás. São Paulo, 153 p. (Tese - Doutorado) - Instituto de Geociências, Universidade de São Paulo.

CORREIA, C.T.; GIRARDI, V.A.V:; TASSINARI, C.C.G.; JOST, H. (no prelo) $\mathrm{Rb}-\mathrm{Sr}$ and $\mathrm{Sm}-\mathrm{Nd}$ geochronology of the Cana Brava layered mafic-ultramafic intrusion, Brazil, and considerations regarding its tectonic evolution. Revista Brasileira de Geociências, submetido para publicação.

DALL'ÁGNOL, R; BETTENCOURT, J.S.; JORGE-SATO, X.S.; MEDEIROS, H.; COSTI, T.H.; MACAMBIRA, J.B. (1987) Granitogenesis in the Northern Brazilian region: a review. Revista Brasileira de Geo- 
ciências, v. 17 , n. 4 , p. 382-403.

D'AGRELLA FILHO, M.S; PACCA, I.G.; ONSTOTT, T.C.; RENNE, P.R; TEIXEIRA, W. (1989) Paleomagmatism and geochronology of mafic dikes from the regions of Salvador, Olivença and Uauá, São Francisco Craton, Brazil: present stage of the USP/Princeton University collaboration. Boletim IG-USP, Série Cientifica, v.20, p.1-8.

DALLA SALDA, L.H.; DALZIEL, I.W.D. (1993) O supercontinente neoproterozóico e as interaçōes Gondwana-Laurentia durante $0 \mathrm{~Pa}$ leozóico Inferior-Médio. Revista Brasileira de Geociências, v. 23, n.3, p. 183-186.

DALLA SALDA, L.H; DALZIEL, I.W.D.; CINGOLANI, C.; VARELA, R. (1992) Did the Tectonic Appalachean continue into South America? Geology, v.20, n.12, p. 1059-1063.

DALMAYRAC, B.; LANCELOT, J.R.; LEYRELOUP, A. (1977) 2 b.y. granulites in the Late Precambrian metamorphic basement along the southern Peruvian coast. Science, v. 198, n. 4312 , p. 49-51.

DALZIEL, I.W.D. (1991) Pacific margins of Laurentia and East AntarticaAustralia as a conjugate rift pair: evidence and implications for an Eocambrian supercontinent. Geology, v. 19, p.598-601.

DALZIEL, I.W.D.; DALLA SALDA, L.H.; GAHAGAN, L.M. (1994) Paleozoic Laurentia-Gondwana interaction and the origin of the Appalachian-Andean mountain system. Geological Society of America Bulletim, v. 106, p. 243-252.

DANDERFER FILHO, A.; LAGOEIRO, L.E.; ALKMIM, F.F. (1993) O Sistema de dobramentos e Empurrões da Chapada Diamantina (BA): registro da inversão do aulacógeno do Espinhaço no decorrer do Evento
Brasiliano. In: SIMPÓSIO SOBRE O CRÁTON DO SÃO FRANCISCO, 2., Salvador, 1993. Anais. Salvador, SBG/SGM, v.1, p.197199.

EBERT, H. (1957) Beitrag zur Gliederung des Prekambriums in Minas Gerais. Geologische Rundschau, v. 45, p. 471-521

EASTON, R.M. (1986) Geochronology of the Grenville Province. In: MOORE, J.M.; DAVIDSON, A; BAER, A.J. (eds.) The Grenville Province. Newfoundland, Geological Association of Canadá, p.127174.

FARIA, A. (1995) Estratigrafia e sistemas deposicionais do Grupo $\mathbf{P a}$ ranoá nas áreas de Cristalina, Distrito Federal e São João d'AliançaAlto Paraíso de Goiás. Brasilia, DF, 199p. (Tese - Doutorado) - Universidade de Brasilia.

FERREIRA, E.O. (1972) Carta Tectônica do Brasil, notícia explicativa. Rio de Janeiro, Ministério das Minas e Energia, Departamento Nacional da Produção Mineral (Boletim n.1). 19p.

FUCK, R.A; BRITO NEVES, B.B.; CORDANI, U.G.; KAWASHITA, K. (1989) Geocronologia Rb-Sr no Complexo Barro Alto, Goiás: evidências de metamorfismo de alto grau e colisão continental há 1300 Ma no Brasil Central. Geochimica Brasiliensis, v.3, n.2, p.125-140.

FUCK, L.A; JARDIM DE SÁ, E.F.; PIMENTEL, M.M; DARDENNE, M.A; PEDROSA SOARES, A.C. (1993) As faixas de dobramentos marginais ao Cráton do São Francisco. In: DOMINGUEZ, J.M.L.; MISIA, A. (eds.) O Cráton do São Francisco. Salvador, SBG/SGM/ CNPq, p. 161-186.

GAUCHER, C.; SPRECHMANN, P. (1995) Paleontologia, sedimentologia y paleogeografia del Proterozóico 
Médio y Superior del Terreno Nico Perez, Unuguay. In: SIMPÓSIO SUL BRASILEIRO DE GEOLOGIA, 1./ENCONTRO DE GEOLOGLA DO CONE SUL 1., Porto Alegre, 1995. Boletim de Resumos Expandidos. Porto Alegre, SBG/ Núcleo RS, p. 101-104.

GOODWIN, A.M. (1991) Precambrian Geology. The dynamic evolution of the continental crust. London, Academic Press, 666p.

GOWER, C.F. (1992) The relevance of Baltic Shield Metallogeny to mineral exploration in Labrador. In: PEREIRA, C.P.G.; WALSH, D.G.; BLACKWOOD, R.F. (eds.) Current Researh. Newfoundland, Geological Survey Branch, p.331-366.

HANCOCK, P. (1994) Continental deformation. Oxford. Pergamon Press, 421p.

HARALYI, N.L.E.; HASUI, Y. (1981) Anomalias gravimétricas e estruturais maiores do sul de Goiás. In: SIMPÓSIO DE GEOLOGIA DO CENTRO-OESTE, 1., Goiânia, 1981. Atas. Goiânia, SBG/Núcleo Centro-Oeste, p.73-92.

HASU, Y.; ALMEIDA, F.F.M. (1976) A Faixa de Dobramentos Uruaçu no Brasil Central. In: CONGRESSO LATINO-AMERICANO DE GEOLOGIA, 3., México, 1976. Resumenes. México, Instituto de Geologia de la Universidad de México, p.62-63.

HASU, Y:; ALMEIDA, F.F.M. (1970) Geocronologia do CentroOeste brasileiro. Boletim da Sociedade Brasileira de Geologia, v. 19, n. 1, p. 5-26.

HASUI, Y; HARALYI, N.L.E. (1986) A mega-estruturação de Goiás. In: SIMPÓSIO DE GEOLOGIA DO CENTRO-OESTE, 2., Goiânia, 1986. Atas. Goiânia, SBG/Núcleo Centro-Oeste, p.120-144.

HATCHER Jr., R.D.; WILLIAMS, H.
(1986) Mechanical model for single thrust sheets and their relationships to the mechanical behavior of orogenic belts. Geological Society of America Bulletin, v. $97, \mathrm{n} .8$, p.975-985.

HERZ, N. (1970) Gneissic and igneous rocks of the Quadrilatero Ferrifero, Minas Gerais, Brazil. U.S. Geological Survey Professional Paper, v. 641, n. B, p. 1-58.

HOFFMAN, P.F. (1991) Did the breakout of Laurentia turn Gondwanaland inside-out? Science, v.252, n.5011, p. 1409-1412.

HSÜ, K.J. (ed.) (1982) Mountain building processes. London. Academic Press, 263p.

INDA, H.A.V:; BARBOSA, J.F (1978) Texto Explicativo para o Mapa Geológico da Bahia Escala 1:1.000.000. Secretaria de Minas e Energia, Governo da Bahia. Coordenação da Produção Mineral, Salvador-Bahia, 137p.

GIRARDI, V.A.V.; KAWASHITA, K. BASEI, M.A.S.; CORDANI, U.G. (1978) Algumas considerações sobre a evolução geológica da região de Cana Brava, a partir de dados geocronológicos. In: CONGRESSO BRASILEIRO DE GEOLOGIA, 30., Recife, 1978. Anais. Recife/SBG, v. 1, p. 337-348.

JARDIM DE SÁ, E.F; BARTELS, E.L.; BRITO NEVES, B.B; McREATH, I. (1976) Geocronologia e o modelo tectonomagmático da Chapada Diamantina e Espinhaço Setentrional, Bahia. In: CONGRESSO BRASILEIRO DE GEOLOGIA, 29. Ouro Preto, 1976. Anais. Ouro Preto, SBG, v. 4, p. 209-226.

JARDIM DE SA, E.F.; McREATH, I; BRITO NEVES, B.B.; BARTELS, R.L.; KAWASHITA, K. (1978) Reconnaissance geochronology of the infrastructure of part of the São Francisco Craton in the State of Bahia, Brazil. Jornal de Mineralogia 
(vol. Djalma Guimarães), v.7, p.8796.

KARFUNKEL, J.; HOPPE, A. (1988) Late Proterozoic glaciation in Central Eastern Brazil: synthesis and model. Paleogeography, Paleoclimatology, Paleoecology, v. 65, n. 1-2, p.1-21.

KINGSTON, D.R; DISHROOM, C.P.; WILLIAMS, P.A. (1983) Global basin classification system. A.A.P.G. Bulletin, v.67, n. 12, p.2173-2193.

KLOOSTERMAN, J.B. (1973) Vulcões gigantes do tipo anelar do Escudo das Guianas. Revista Mineraçâo Metalurgia, v.36, n.341, p.5258.

KROONENBERG, S.B. (1982) A Grenvillian granulite belt in the Colombian Andes and its relation to the Guiana Shield. Geologic en Mijnbow, v.61, n.4, p.325-333.

LEAL, J.W.L.; SILVA, G.H.; SANTOS, D.B.; TEXEIRA, W.; LIMA, M.I.C; FERNANDES, C.A.C.; PINTO, A.C. (1978) Geologia. In: Projeto RADAMBRASIL. Folha SC.20 Porto Velho. Rio de Janeiro, MME, DNPM. p.19-184. (Levantamento Narurais, 16).

LEDRU, P.; JOHAN, V; MIIESI, J.P.; TEGYEY, M. (1994) Markers of the last stages of the Paleoproterozoic collision: evidences for a $2 \mathrm{Ga}$ continent involving circum-South Atlantic provinces. Precambrian Research, v. 69, n. 1-4,169-191.

LESQUER, A; ALMEIDA, F.F.M; DAVINO, A; LACHAUD, J.C; MAILLARD, P. (1981) Signification structurale des anomalies gravimetriques de la parte sud du Craton de São Francisco (Brésil). Tectonophysics, v.76, n.3-4, p. 273-293.

LIMA, M.I.C; MONTALVÃO, R.M. G.; ISLER, R.S.; OLIVEIRA, A.S.; BASEI, M.A.S.; ARAUJO, J.F.V.; SILVA, G.G. (1974) Geologia. In: Projeto RADAMBRASIL Folha NA/NB-22 Macapá. Rio de Janeiro,
MME,DNPM. p. 1-120 (Levantamento de Recursos Naturais, 6).

LITHERLAND, M.; ANNELLS, R.N.; APPLETON, J.D; BERRANGÉ, J.P.; BLOOMFIELD, K; BURTON, C.C.J.; DARBYSHIRE, D.P. F.; FLETCHER, C.J.N.; HAWKINS, M.P.; KLINCK, B.A.; LIANOS, A: MITCHELL, M.I.; O'CONNOR, E.A; PITFIELD, P.E.J.; POWER, G.; WEBB, B.C. (1986) The geology and mineral resources of the Bolivian Precambrian shield. Overseas Memoir, n. 19, p.1153.

LITHERLAND, M; KLINCK, B.A.; O'CONNOR, E.A.; PITFIELD, P.E.J. (1985) Andean-trending mobile belts in the Brazilian Shield. Nature, v.314, n.6009, 345-348.

MACHADO, N.; SCHRANK, A.; ABREU, F.R; KNAUER, L.G.; ABREU, P.A.A. (1989) Resultados preliminares da geocronologia U-Pb na Serra do Espinhaço Meridional. In: SIMPÓSIO DE GEOLOGIA DE MINAS GERAIS, 5., Belo Horizonte, 1989. Anais. Belo Horizonte, SBG/Núcleo de Minas Gerais, p.171174.

MARINI, O.J.; FUCK, R.A; DARDENNE, M.A; DANNI, J.M.C. (1984) Província Tocantins. Setores Central e Sudeste. In: ALMEIDA F.F.M; HASUI, Y. (coords.) O Pré-Cambriano do Brasil. São Paulo, Edgard Blücher, p.205-264.

MARSHAK, S.; ALKMIM, F.F. (1989) Proterozoic contraction/extension tectonics of the Southern São Francisco region, Minas Gerais, Brazil. Tectonics, v.8, n.3, p.555571.

MASCARENHAS, J.F.; GARCIA, T.W. (1989) Mapa geocronológico do Estado da Bahia: Texto Explicativo. Salvador, Secretaria de Minas e Energia da Bahia, Superintendência de Geologia e Recursos 
Minerais, $189 p$.

MATHENEY, R.K; BROOKINS, D.G.; WALLIN, E.T; SHAFIQULLAH, M. DAMON, P.E. (1990) Incompletely reset $\mathrm{Rb}-\mathrm{Sr}$ systems from a Cambrian red-rock granophyre terrane, Florida Mountains, New Mexico, U.S.A. Chemical Geology, v.86, n. 1, p.29-47.

MOORE, J.M; DAVIDSON, A; BAER, A.J. (eds.) (1986) The Grenville Province. Toronto, Geological Association of Canada. (Geological Association of Canada. Special Paper. 31).

MOORES, E.M. (1991) Southwest U.S.-East connection: a hypothesis. Geology, v. 19 , n. 5, p. $425-428$.

MORAES-BRITO, C.; BELLIENI, G.; CHIARAMONTI, P.C.; MELFI, A.; PICCIRILLO, E.M.; OLIVEIRA, M.A.F.T. (1989) Geological and petrological characteristics. Boletim IG-USP, Série Científica, v.20, p.914.

OLIVEIRA, M.A.F.T; BELLIENI, G.; CHIARAMONTI, P.C; MELFI, A.J.; PICCIRILLO, E.M; MORAES-BRITO, C. (1989) Preliminary petrographic and geochemical considerations on the precambrian mafic dykes of the Ilhéus-Olivença area, Bahia. Boletim IG-USP, Série Científica, v.20, p.15-19.

PEDROSA SOARES, A.C.; NOCE, C.M; VIDAL, P.; LEONARDOS, O.H.; LOBATO, L.M; CARVALHO, C.T.; MAGNI, M.C.V.; FARIA, L.F. (1992) Novo modelo evolutivo para a Faixa Araçuai: dados complementares e síntese. In: CONGRESSO BRASILEIRO DE GEOLOGIA, 37., São Paulo, 1992. Boletim de Resumos Expandidos. São Paulo, SBG, v.1, p. 287-288.

PIMENTEL, M.M.; HEAMAN, L; FUCK, R.A. (1991) Zircon and sphene U-Pb geochronology of Upper Proterozoic volcanic-arc rock units from southwestern Goiás, Central Brasil. Journal of South American Earth Sciences, v.4, n.4, 295-305.

PIMENTEL, M.M.; HEAMAN, L.; FUCK, R.A.; MARINI, O.J. (1991) $\mathrm{U}-\mathrm{Pb}$ zircon geochronology of Precambrian tin-bearing continental type acid magmatism in Central Brasil. Precambrian Research, v. 52 , n. 3-4, p. 321-335.

PIMENTEL, M.M.; MACHADO, N.; LOBATO, L.M. (1994) Geocronologia U-Pb de rochas graníticas da região de Lagoa Real, Bahia, e implicações para a idade da mineralização de urânio. In: CONGRESSO BRASILEIRO DE GEOLOGIA, 38, Balneário Camboriú, 1994. Boletim de Resumos Expandidos. Balneário de Camboriú, SBG, v.2, p.389-390.

PLUMB, K.A. (1991) New Precambrian time scale. Episodes, v.14, n.2, p. 139-140

PORADA, H. (1989) Pan-African rifting and orogenesis in Southern to Equatorial Africa and Eastern Brazil. Precambrian Research, v.44, n.2, p. 103-136.

PRIEM, H.N.A.; BOELRIJK, N.A. I.M.; HEBEDA, E.H.; VERDURMEN, E.A.Th; VERSCHURE, R.H. (1971) Isotopic ages of the Trans-Amazonian acidic magmatism and the Nickerie metamorphic episode in the Precambrian Basement of Suriname, South America. Geological Society of America Bulletin, v.82, n.6, p. 1668-1680.

RAMOS, V.A. (1988) Late Proterozoic - Early Paleozoic of South America a collisional history. Episodes, v.11, n.3, p.168-174.

RAMOS, V.A. (1989) The birth of Southern South American. American Scientist, v.77, n.5, p.444-450.

RAMOS, V.A.; McDONOUGH, M. BOWRNG, S.; ISACHSEN, C.F.; VUJOVICH, G. (no prelo) Western 
Sierras Pampeanas. A grenvillean orogen of Central Argentina.

RAMOS, V.A.; VUJOVICH, G. (1993) The Pampia Craton within western Gondwanaland. In: CIRCUM-PACIFIC AND CIRCUMATLANTIC TERRANE CONFERENCE, 1,, 1993. Proceedings. Guajanato, Universidad Autonoma de México, p.113-116.

REIS NETO, J.M. (1983) Evolução geotectônica da Bacia do Alto Tocantins. São Paulo, 98p. (Dissertação - Mestrado) - Instituto de Geociências, Universidade de São Paulo.

REIS NETO, J.M. (1994) Faixa Itaiacoca: registro de uma colisão entre dois blocos continentais no Neoproterozóico. São Paulo, 300p. (Tese - Doutorado) - Instituto de Geociências, Universidade de São Paulo.

REIS NETO, J.M; CORDANI, U.G. (1984) Influência de evento geodinâmico Brasiliano nos resultados radiométricos do Centro-Oeste brasileiro. In: CONGRESSO BRASILEIRO DE GEOLOGIA, 33., Rio de Janeiro, 1984. Anais. Rio de Janeiro, SBG, v. 4, p.2276-2288.

ROCHA, G.M.F.; DOMINGUEZ, J.M. L. (1993) As fases de deformação brasiliana atuantes nos Supergrupos Espinhaço e São Francisco no Estado da Bahia. In: SIMPÓSIO SOBRE O CRÁTON DO SÃO FRANCISCO, 2., Salvador, 1993. Anais. Salvador, SBG/SGM, v.1, p. 200-204.

ROGERS, J.J.W. (1996) A history of continents in the past three billions years. Journal of Geology, v.104, n. 1, p.91-107.

SÁ, J.M. (1991) Evolution geodynamique de la Ceinture Proterozoic d'Orós Nord-Est du Brésil. Nancy, 177p. (Tese - Doutorado) - Universidade de Nancy.

SADOWSKI, G.R; BETTENCOURT, J.S. (1996) Mesoproterozoic tectonic correlations between eastern
Laurentia and the western border of the Amazon Craton. Precambrian Research, v. 76, n. 3-4, p. 213-228.

SANTOS, E.J.; BRITO NEVES, B.B.; VAN SCHMUS, W.R. (1995) O complexo granítico Lagoa das Pedras: acresção e colisão na região de Floresta (Pernambuco), Provincia de Borborema. In: SIMPÓSIO DE GEOLOGIA DO NORDESTE, 16. Recife, 1995. Atas. Recife, SBG, Núcleo Nordeste, v.2, bol.14, p.401405 .

SANTOS, J.O.S.; OLIVEIRA, J.R. (1978) Magmatismo básico-alcalino no Proterozóico Superior da Plataforma Amazônica. In: CONGRESSO BRASILEIRO DE GEOLOGIA, 30., Recife, 1978. Anais. Recife, SBG, v.3, p. 1309-1322.

SANTOS, J.O.S.; OLIVEIRA, J.R. (1980) Principais associaçōes máficas não metamórficas da Plataforma Amazônica. In: CONGRESSO BRASILEIRO DE GEOLOGIA, 31., Balneário Camboriú, 1980. Anais. Balneário Camboriú, SBG, v.4, p. 2253-2262.

SENGÖR, A.M.C. (1990) Plate tectonics and orogenic research after 25 years: a tethyan perspective. Earth Science Review, v.27, n.1-2, p.1201.

SOUZA FILHO, R.G.; ALKMIM, F.F. (1993) A discordância angular entre os Supergrupos Espinhaço e São Francisco e o arcabouço estrutural da região da Serra do Cabral, MG. In: SIMPÓSIO SOBRE O CRÁTON DO SÃO FRANCISCO, 2., Salvador, 1993. Anais. Salvador, SBG/ SGM, v.1, p.212-214.

SUAREZ, A.F. (1990) The basement of the Eastern Cordillera, Colombia: an allochthonous terrane in northwestern South America. Journal of South American Earth Sciences, v.3, n.23, p. 141-151.

SUTTA, M.F.T; KAMO, S.L.; 
KROGH, T.E.; FYFE, W.S.; HARTMANN, L.A. (1994) U-Pb ages from the high-grade Barro Alto mafic-ultramafic complex (Goiás, Central Brasil): Middle Proterozoic continental mafic magmatism and Upper Proterozoic continental collision. In: INTERNATIONAL CONFERENCE ON GEOCHRONOLOGY, COSMOCHRONOLOGY. AND ISOTOPE GEOLOGY, 8., Berkeley, 1994. Abstracts. Berkeley, ICOG, p.309.

SUTTON, J. (1963) Long-term cycles in the evolution of the continents. Nature, v. 198 , n. 4882 , p.731-733.

TASSINARI, C.C.G. (1981) Evolução geotectônica da Província Rio Negro-Juruena na região amazônica. São Paulo, 99p. (Dissertação - Mestrado) - Instituto de Geociências, Universidade de São Paulo.

TASSINARI, C.C.G.; CORDANI, U.G.; NUTMAN, A.P.; BETTENCOURT, J.S.; VAN SCHMUS, W.R. (1995) Geochronological systematics on basement rocks from Rio Negro-Juruena Province, Brazil and tectonic implications. In: SYMPOSIUM ON RAPAKIVI GRANITES AND RELATED ROCKS. Belém, 1995. Abstracts. Belém, IGCP Project 315/Centro de Geociências da UFPA, p. 77.

TASSINARI, C.C.G.; SIGA Jr., O; TEIXEIRA, W. (1986) Panorama geocronológico do centro-oeste brasileiro: soluções, problemática e sugestões. In: SIMPÓSIO DE GEOLOGIA DO CENTRO-OESTE, 1 , Goiânia, 1991. Atas. Goiânia, SBG/ Núcleo Centro-Oeste e Brasília, v.1, p.93-116.

TEIXEIRA, W. (1989) Mafic dikes in the Southern part of the São Francisco Craton: a tectonic review based on $\mathrm{K} / \mathrm{Ar}$ geochronology. Boletim IG-USP, Série Científica, v. 20, p. 25-30.
TEIXEIRA, W. (1990) The Proterozoic mafic dike swarms and alkaline intrusions in the Amazonian Craton, South America, and their tectonic evolution based on $\mathrm{Rb}-\mathrm{Sr}, \mathrm{K}-\mathrm{Ar}$ and ${ }^{40} \mathrm{Ar}-{ }^{39} \mathrm{Ar}$ geochronology. In: PARKER, A.J.; RICKWOOD, P.C.; TUCKER, D.H. (eds.) Mafic dikes and emplacement mechanisms, Rotterdan, Balkema, p. 285-293.

TEIXEIRA, W; RENNE, P.R; BOSSI, J.; CAMPAL, N. (1994) Geocronologia $\mathrm{Ar}^{40} / \mathrm{Ar}^{39}$ e $\mathrm{Rb} / \mathrm{Sr}$ dos diques máficos pré-cambrianos do Cráton Rio de La Plata: idade, distúrbios isotópicos e inferências tectônicas. In: CONGRESSO BRASILEIRO DE GEOLOGIA, 38., Balneário de Camboriú, 1994. Boletim de Resumos Expandidos. Balneário de Camboriú, SBG, v.2, p.384-385.

TURPIN, L.; MARUEJOL, P.; CUNEY, M. (1988) U-Pb, Rb-Sr and $\mathrm{Sm}-\mathrm{Nd}$ chronology of granitic basement, hydrothermal albitites and uranium mineralizations (Lagoa Real, South Bahia, Brazil). Contribution to Mineralogy and Petrology, v.98, n. 2, p. 139-147.

VAN SCHMUS, W.R. BICKFORD, M.E.; CONDIE, K. (1993) Early Proterozoic crustal evolution. In: REDDE, J.C; BICKFORD, M.E.; HOUSTON, R.S.; LINK, P.K. RANKIN, D.W; SIMS, P.K.; VAN SCHMUS, W.R. (eds.) Precambrian: conterminous U.S. Boulder, Geological Society of America, The Geology of North America, v.C-2, p. 270-281.

VAN SCHMUS, W.R; BRITO NEVES, B.B.; HACKSPACHER, P.; BABINSKI, M. (1995) U/Pb and $\mathrm{Sm} / \mathrm{Nd}$ geochronologic studies of the Eastern Borborema Province, Northeast Brazil: initial conclusions. Journal of South American Earth Sciences, v. 8 , n.3/4, p.267-288.

VAN SCHMUS, W.R; TASSINARI, 
C.C.G.; CORDANI, U.G. (1986) Estudo geocronológico de parte inferior do Grupo São Roque. In: CONGRESSO BRASILEIRO DE GEOLOGIA, 36., Goiânia, 1986. Anais. Goiânia, SBG, v.3, p.13991406.

VUJOVICH, G.I.; RAMOS, V.A. (1993) The Western Sierras Pampeanas Island Arc Terranes. In: CIRCUM-PACIFIC AND CIRCUMATLANTIC TERRANE CONFERENCE, 1. Proceedings, 1993. Guajuanato, Universidad Autonoma de
México, p. 166-169

WINDLEY, B. (1995) The evolving continents. 3.ed. Chichester, John Wiley, 526p.

WINGE, M. (1995) Evolução dos terrenos granulíticos da Província Estrutural Tocantins, Brasil Central. Brasilia, 207p. (Tese - Doutorado) - Instituto de Geociências, Universidade de Brasilia).

XINGYUAN, M. (1988) Lithospheric dynamics of China. Episodes, v.11, n. 2, p. $84-90$.

B.B.Brito Neves - Instituto de Geociências, Universidade de São Paulo, Caixa Postal 11.348, CEP 05422-970, São Paulo, SP, Brasil. 